\title{
La identificación de factores en el desarrollo de competencias de los estudiantes universitarios. Un estudio exploratorio
}

\section{The identification of factors in the competences development of university students. An exploraty study}

\author{
$M^{a}$ Covadonga DE LA IGLESIA \\ Universidad Complutense de Madrid
}

Recibido: Mayo 2011

Aceptado: Marzo 2012

\section{Resumen}

En este trabajo se presentan los resultados de la búsqueda de factores que expliquen el grado de desarrollo en competencias de los alumnos de cuarto y quinto curso de las titulaciones de Administración y Dirección de Empresas y de Economía (ADE y ECO) de la UCM y la UAH. Se realiza una encuesta que proporciona información comparativa sobre la percepción que los estudiantes tienen de su grado de desarrollo competencial y la valoración de lo relevante que es el mismo en el entorno laboral. Como datos identificativos de la muestra de datos, cabe señalar que el $49,55 \%$ son varones, el $42,57 \%$ cursa quinto año de licenciatura, el $34,45 \%$ estudia ECO y el $65,31 \%$ declara tener experiencia profesional previa; además, las féminas muestran un mayor acercamiento al entorno laboral durante su etapa formativa, dado que el 55,19\% de los que declaran no tener experiencia laboral son varones. El análisis factorial realizado identifica cuatro factores "sólidos" en la estructura del constructo obtenido, que permitirían establecer un indicador consistente de evaluación del grado de desarrollo en competencias y su importancia en el entorno laboral.

Palabras clave: desarrollo de competencias, análisis factorial, métodos de enseñanza, inserción laboral.

\begin{abstract}
This paper presents the results of the search for factors that explain the skills development of university students in fourth and fifth year the degree in Business Administration and Economics (ADE and ECO) of the UCM and UAH. The survey aims to provide comparative information on the perception that students are developing their level of competence and their assessment of how relevant is the same in the workplace. As identification data of the sample of students surveyed, it is noted that $49.55 \%$ are male, $42.57 \%$ is in the fifth year of undergraduate study $34.45 \%$ and $65.31 \%$ ECO states have professional experience prior, with no significant differences between the subsamples of college. Also point out that females show slightly closer to the work environment during their formative stage, as the $55.19 \%$ who report no work experience are male. The factor analysis identified four factors "solid" in the structure of the
\end{abstract}


builder obtained, which would establish a consistent indicator to assess the degree of development skills and its importance in the workplace.

Key words: Skills development, factor analysis, teaching methods, labour insertion.

La Universidad, hoy más que nunca, tiene como reto consolidar una mejora en la calidad de la enseñanza superior y tener un mejor conocimiento de la efectividad docente, en un contexto de cambio metodológico y adaptación al EEES. Dicho cambio va dirigido a que los estudiantes durante su proceso formativo desarrollen y asimilen, no solo los conocimientos propios de su titulación, sino también las competencias específicas y genéricas, así como las habilidades transversales que demanda su entorno profesional, en un mundo claramente competitivo y globalizado, con una orientación de la enseñanza universitaria hacia el aprendizaje activo.

La motivación de esta línea de trabajo es analizar la percepción de los propios estudiantes sobre su grado de desarrollo competencial frente a la valoración que hacen de la importancia del mismo en el entorno laboral. Recoge un campo de investigación habitual en los estudios de inserción laboral, y en este contexto cabe destacar el trabajo de Iriondo y otros (2009), que estudia distintos ítems de la satisfacción de los egresados con el proceso formativo a partir de la encuesta de inserción laboral realizada a los egresados de la Universidad Complutense de Madrid ${ }^{1}$. Obtienen en general que la valoración que hacen los licenciados de la preparación recibida en la Universidad para su desarrollo competencial fue insuficiente en la mayoría de los casos, con diferenciales en los porcentajes de acumulación de respuestas entre las distintas opciones que muestran que la Universidad aportó "poco" a su preparación, a excepción de nuevos conocimientos, "adecuada" en cuanto a los contenidos de los programas teóricos e "insuficiente" en las áreas de idiomas, informática y capacidad creativa de los licenciados.

El concepto de competencia es amplio y diverso, según el énfasis que se le dé a los diversos aspectos. Mientras que en español utilizamos diversos términos como habilidades, destrezas, competencias, calificaciones, aptitudes y/o talentos, no siempre sinónimos entre sí, en inglés todos ellos se denominan "skills", si bien el significado concreto está ligado al contexto del vocablo. Conceptualmente existen importantes diferencias entre el término habilidades y competencias, como señala Climent (2010), dado que una habilidad es una "herramienta" causativa del desempeño de una persona (Holmes, 2000), dentro o fuera de la realidad social o laboral en que ésta vive, mientras que "competencia", en cambio, es la capacidad que permite instrumentar de forma adecuada un conjunto de habilidades, conocimientos y valores, para realizar exitosamente una tarea, en determinadas circunstancias sociales o laborales. Centrándonos en el término competencias, Sladogna (2000) las define como capacidades complejas que poseen distintos grados de integración y se manifiestan en una gran variedad de situaciones en los diversos ámbitos de la vida humana, personal y social, siendo una síntesis de las experiencias que el sujeto ha logrado construir en el marco de su entorno

\footnotetext{
${ }^{1}$ La encuesta se realizó a egresados en el curso 2001/02, y aporta información en dos períodos de tiempo, tras finalizar los estudios y cinco años después.
} 
vital, amplio, pasado y presente. Otra idea interesante la sostiene Masseilot (2000), para quien el concepto de competencia es elástico y flexible, y está dirigido a superar la brecha entre trabajo intelectual y manual. Añade Vargas (2000) que las características esenciales de la competencia laboral son estar orientada al desempeño en el trabajo, en situaciones definidas, ser contrastada ante un patrón o norma de desempeño esperado, e incluir un gran acervo de capacidades personales y sociales.

Este trabajo no trata de ahondar en los ya estandarizados catálogos de definiciones, aspectos y enfoques del marco conceptual que se han dado en la literatura sobre la educación basada en competencias y sus aspectos relevantes. Pero sí que, recogiendo los enfoques expuestos, se parte de considerar que el desarrollo de las competencias de un adulto están marcadas tanto por sus propias e inherentes habilidades como por las características de la educación recibida, y que se consolidan con la experiencia articulada por su vida personal, social y laboral. Así, el trabajo aborda el análisis de las asimetrías entre el grado de desarrollo competencial y la relevancia en el entorno laboral, pero desde la perspectiva de la valoración del propio estudiante, según su propia experiencia, personal, laboral, social, y entorno de formación.

El trabajo se subdivide en tres apartados. El primero aporta la nota metodológica de la investigación realizada, con un breve análisis descriptivo de la base de datos utilizada. En el segundo apartado se presentan los instrumentos y resultados del análisis factorial realizado que permite identificar para el conjunto de ítems o variables estudiadas un número reducido de factores latentes, constructos o dimensiones subyacentes significativas, a través del estudio de la matriz de covariancia asociada a los datos, que trazan un mapa exploratorio ${ }^{2}$ del desarrollo competencial de los estudiantes universitarios encuestados. Este análisis factorial permite establecer un instrumento útil para la evaluación de las competencias adquiridas y el grado potencial de uso en el entorno laboral de los estudiantes universitarios. Finaliza el trabajo con una discusión sobre los resultados y conclusiones que justifican, de alguna manera, la pertinencia de este tipo de trabajo, dada la necesaria adecuación que el futuro egresado debe tener en su desarrollo competencial con los requerimientos del mercado.

\section{Metodología y base de datos}

\section{Diseño}

En este trabajo se utiliza la información estadística obtenida en la encuesta a estudiantes realizada en el Proyecto de Innovación y Mejora de la Calidad Docente, "Plan de Mejora docente de la formación en competencias genéricas de los estudiantes. De

\footnotetext{
${ }^{2}$ Dado el ámbito y objetivo de este trabajo, meramente descriptivo y exploratorio de la estructura de la encuesta realizada, no se aborda un análisis factorial confirmatorio, que podría realizarse en fases posteriores, siguiendo las pautas de Henson y Roberts (2006).
} 
la Universidad al entorno laboral", ${ }^{\prime 3}$, cuyo objetivo es proporcionar una información comparativa sobre la percepción que los estudiantes tienen de su grado de desarrollo competencial y la valoración que hacen de lo relevante que es el mismo en el entorno laboral, según sus vivencias previas.

\section{Variables y muestra}

La encuesta realizada recoge los datos de la opinión de 444 estudiantes, aquellos que estaban presentes en sus aulas en la tercera semana del mes de enero de 2010, y que estaban matriculados en cuarto o quinto curso de las licenciaturas de "Administración y Dirección de Empresas" [ADE] o "Economía" [ECO], en las Facultades de Ciencias Económicas y Empresariales (CCEE) de las Universidades Complutense de Madrid (UCM) y Alcalá de Henares (UAH). La selección de los cursos, cuarto y quinto, se realizó dado que los estudiantes ya tienen un criterio más certero del entorno laboral, muchos de ellos están o han realizado prácticas en empresa, o han tenido una experiencia profesional previa.

El cuestionario ${ }^{4}$ utilizado recoge un listado exhaustivo de 40 competencias genéricas, tratadas como variables independientes en el análisis. Las preguntas asociadas a las diversas competencias se presentan en dos bloques simétricos con una valoración numérica en escala de Likert que va del 1 ("nada") al 5 ("mucho"), según que se refiera a su grado de desarrollo competencial o preparación en la formación universitaria $(P U)$ o cómo creen que es de importante en el entorno laboral para el desempeño de la actividad profesional (IT). Este cuestionario sigue las pautas del estudio Tuning y es habitual, con adaptaciones, en estudios en los que se trata de evaluar las competencias genéricas adquiridas en la educación superior, independientemente de que se recabe la opinión de los propios estudiantes o de los empleadores y/o académicos, como en el trabajo de Palmer, Montaño y Palou (2009), quienes utilizan la misma escala definida de 1 a 5 . Además se dispone de información individual como el sexo, la edad, la licenciatura y la especialidad que cursa, así como la experiencia laboral. La estructura del cuestionario es como sigue:

\begin{tabular}{|l|c|c|c|c|c|c|c|c|c|c|}
\hline & \multicolumn{4}{|c|}{ Grado de Preparación en la universidad } & \multicolumn{5}{c|}{ Importancia que cree tiene en el trabajo } \\
\hline & Nada & Poco & Regular & Bastante & Mucho & Nada & Poco & Regular & Bastante & Mucho \\
\cline { 2 - 11 } & 1 & 2 & 3 & 4 & 5 & 1 & 2 & 3 & 4 & 5 \\
\hline Liderazgo & & & & & & & & & & \\
\hline
\end{tabular}

Una primera exploración, descriptiva y exhaustiva de los datos se puede consultar en Iglesia e Ionita (2010). La muestra estudiada se caracteriza porque el 49,55\% de los

${ }^{3}$ Financiado por el Vicerrectorado de Desarrollo y Calidad Docente de la UCM. El equipo de investigación está integrado por los profesores Galleo, E., Gracia, E., Iriondo, I. y De la Iglesia, M.C., siendo ésta la responsable.

${ }^{4}$ El listado de competencias analizadas viene especificado en las tablas del texto y anexos. 
alumnos encuestados son varones, el $42,57 \%$ está inscrito en el quinto año de la licenciatura, el $34,45 \%$ estudia ECO y el $65,31 \%$ declara tener cierta experiencia profesional previa, bien sea por haber realizado prácticas o por trabajos temporales y esporádicos. Ahondando en la caracterización de la base de datos, tal como muestra la tabla 1 siguiente, entre los alumnos matriculados en cuarto curso el 47,45\% son varones, porcentaje que asciende al 52,23\% en los grupos de quinto curso. Segmentando la base de datos por tipo de estudios, el 50,86\% de los alumnos que estudian ADE son varones, mientras que en ECO los varones representan únicamente el 47,06\%. Cabe destacar un menor acercamiento al entorno laboral de los varones durante su etapa formativa, frente a sus compañeras féminas, pues entre los estudiantes que declaran no tener experiencia laboral previa el porcentaje de varones es del 55,19\%.

\begin{tabular}{|c|c|c|c|}
\hline \multicolumn{2}{|c|}{$4^{\circ}$ curso $[57,43 \%$ del total] } & \multicolumn{2}{c|}{$5^{\circ}$ curso } \\
\hline Varones & Mujeres & Varones & Mujeres \\
\hline $47,45 \%$ & $52,55 \%$ & $52,23 \%$ & $47,77 \%$ \\
\hline ADE $[65,5 \%$ del total] & \multicolumn{2}{|c|}{ ECO } \\
\hline Varones & Mujeres & Varones & Mujeres \\
\hline $50,86 \%$ & $49,14 \%$ & $47,06 \%$ & $52,94 \%$ \\
\hline SIN experiencia profesional & {$[34,68 \%$ del total] } & CON experiencia profesional \\
\hline Varones & Mujeres & Varones & Mujeres \\
\hline $55,19 \%$ & $44,81 \%$ & $46,55 \%$ & $53,45 \%$ \\
\hline
\end{tabular}

Tabla 1. Distribución de datos por curso, titulación y experiencia, según sexo (\% sobre el total de la segmentación), [\% sobre el total de la muestra]

Fuente: Encuesta de Necesidad de Desarrollo Competencial. Elaboración propia.

\section{Análisis descriptivo de los datos}

A continuación se presenta un análisis descriptivo de los datos de la encuesta de valoración del desarrollo en competencias, ordenado el listado de variables en bloques, a efectos de poder seguir con mayor facilidad los comentarios.

\section{Primer bloque de competencias}

El primer bloque de competencias analizadas muestra (tabla 2) el diferencial en la valoración entre ambas preguntas. La importancia en el trabajo, en general, es superior a 3,4, llegando a la cota superior de alrededor de 4,3 en la "comunicación oral y escrita en lengua materna", "utilizar herramientas informáticas" y "toma de decisiones". Respecto al grado de preparación, las medias oscilan entre el 2,1 de "comunicación oral y escrita", y el 3,4 de "comunicación oral y escrita en lengua materna", "pensamiento analítico y capacidad de síntesis", y el 3,3 de "organización y planificación" y "adquirir con rapidez nuevos conocimientos".

Al segmentar la información por submuestras, en general la valoración media de los varones es ligeramente superior a la de sus compañeras las féminas, en todas las competencias cuando se refiere a la importancia en el trabajo, y con excepciones con dife- 
renciales limitados en lo que respecta al grado de preparación en la Universidad, como son "pensamiento analítico y capacidad de síntesis, utilizar herramientas informáticas o búsqueda de información en diversas fuentes". Además, en la segmentación por experiencia profesional, como regla, para el total de alumnos la valoración media del grado de desarrollo o preparación en la Universidad de las competencias es mayor cuando tienen experiencia. Sin embargo, esta unanimidad no se confirma respecto a la importancia en el trabajo.

\begin{tabular}{|l|c|c|c|c|c|c|}
\hline \multirow{2}{*}{$\begin{array}{c}\text { Competencias } \\
\text { Primer bloque }\end{array}$} & \multicolumn{3}{c|}{ PU } & \multicolumn{3}{c|}{ IT } \\
\cline { 2 - 7 } & Varones & Mujeres & Todos & Varones & Mujeres & Todos \\
\hline $\begin{array}{l}\text { Pensamiento Analítico y Capacidad de } \\
\text { síntesis }\end{array}$ & 3,368 & 3,406 & 3,387 & 4,064 & 3,830 & 3,946 \\
\hline Organización y Planificación & 3,486 & 3,196 & 3,340 & 4,418 & 4,143 & 4,279 \\
\hline $\begin{array}{l}\text { Comunicación oral y escrita en lengua } \\
\text { materna }\end{array}$ & 3,555 & 3,388 & 3,471 & 4,395 & 4,246 & 4,320 \\
\hline $\begin{array}{l}\text { Comunicación oral y escrita en lengua } \\
\text { extranjera }\end{array}$ & 2,164 & 2,147 & 2,155 & 4,350 & 4,112 & 4,230 \\
\hline Utilizar herramientas informáticas & 2,800 & 2,862 & 2,831 & 4,505 & 4,241 & 4,372 \\
\hline $\begin{array}{l}\text { Búsqueda de información en diversas } \\
\text { fuentes }\end{array}$ & 3,241 & 3,299 & 3,270 & 4,032 & 3,661 & 3,845 \\
\hline Resolución de conflictos o problemas & 2,882 & 2,804 & 2,842 & 4,268 & 4,045 & 4,155 \\
\hline Toma de decisiones & 2,959 & 2,866 & 2,912 & 4,436 & 4,174 & 4,304 \\
\hline Conocimientos de otras áreas o disciplinas & 2,891 & 2,656 & 2,773 & 3,632 & 3,313 & 3,471 \\
\hline Adquirir con rapidez nuevos conocimientos & 3,427 & 3,228 & 3,327 & 4,177 & 3,777 & 3,975 \\
\hline
\end{tabular}

\begin{tabular}{|c|c|c|c|c|}
\hline \multirow{3}{*}{$\begin{array}{l}\text { Competencias } \\
\text { Primer bloque }\end{array}$} & \multicolumn{2}{|c|}{$P U$} & \multicolumn{2}{|c|}{ IT } \\
\hline & \multicolumn{2}{|c|}{ Experiencia laboral } & \multicolumn{2}{|c|}{ Experiencia laboral } \\
\hline & $S I$ & $\mathrm{NO}$ & $S I$ & $\mathrm{NO}$ \\
\hline $\begin{array}{l}\text { Pensamiento Analítico y Capacidad de } \\
\text { síntesis }\end{array}$ & 3,409 & 3,376 & 3,948 & 3,945 \\
\hline Organización y Planificación & 3,461 & 3,276 & 4,273 & 4,283 \\
\hline $\begin{array}{l}\text { Comunicación oral y escrita en lengua } \\
\text { materna }\end{array}$ & 3,545 & 3,431 & 4,377 & 4,290 \\
\hline $\begin{array}{l}\text { Comunicación oral y escrita en lengua } \\
\text { extranjera }\end{array}$ & 2,305 & 2,076 & 4,299 & 4,193 \\
\hline Utilizar herramientas informáticas & 2,981 & 2,752 & 4,318 & 4,400 \\
\hline $\begin{array}{l}\text { Búsqueda de información en diversas } \\
\text { fuentes }\end{array}$ & 3,351 & 3,228 & 3,812 & 3,862 \\
\hline Resolución de conflictos o problemas & 3,013 & 2,752 & 4,084 & 4,193 \\
\hline Toma de decisiones & 3,084 & 2,821 & 4,292 & 4,310 \\
\hline Conocimientos de otras áreas o disciplinas & 2,818 & 2,748 & 3,513 & 3,448 \\
\hline Adquirir con rapidez nuevos conocimientos & 3,357 & 3,310 & 3,877 & 4,028 \\
\hline \multirow{2}{*}{$\begin{array}{l}\text { Competencias } \\
\text { Primer bloque }\end{array}$} & \multicolumn{2}{|c|}{4 curso } & \multicolumn{2}{|c|}{$5^{\circ}$ curso } \\
\hline & PU & _IT & $\ldots \boldsymbol{P U}$ & IIT \\
\hline $\begin{array}{l}\text { Pensamiento Analítico y Capacidad de } \\
\text { síntesis }\end{array}$ & 3,349 & 3,949 & 3,439 & 3,942 \\
\hline
\end{tabular}




\begin{tabular}{|l|c|c|c|c|}
\hline Organización y Planificación & 3,275 & 4,263 & 3,429 & 4,302 \\
\hline $\begin{array}{l}\text { Comunicación oral y escrita en lengua } \\
\text { materna }\end{array}$ & 3,455 & 4,333 & 3,492 & 4,302 \\
\hline $\begin{array}{l}\text { Comunicación oral y escrita en lengua } \\
\text { extranjera }\end{array}$ & 2,086 & 4,224 & 2,249 & 4,238 \\
\hline Utilizar herramientas informáticas & 2,757 & 4,427 & 2,931 & 4,296 \\
\hline $\begin{array}{l}\text { Búsqueda de información en diversas } \\
\text { fuentes }\end{array}$ & 3,216 & 3,929 & 3,344 & 3,730 \\
\hline Resolución de conflictos o problemas & 2,800 & 4,200 & 2,899 & 4,095 \\
\hline Toma de decisiones & 2,937 & 4,322 & 2,878 & 4,280 \\
\hline Conocimientos de otras áreas o disciplinas & 2,753 & 3,549 & 2,799 & 3,365 \\
\hline Adquirir con rapidez nuevos conocimientos & 3,353 & 4,043 & 3,291 & 3,884 \\
\hline
\end{tabular}

\begin{tabular}{|l|c|c|c|c|}
\hline \multicolumn{1}{|c|}{$\begin{array}{l}\text { Competencias } \\
\text { Primer bloque }\end{array}$} & \multicolumn{2}{c|}{ ECO } & \multicolumn{2}{c|}{ ADE } \\
\cline { 2 - 5 } & PU & IT & PU & IT \\
\hline $\begin{array}{l}\text { Pensamiento Analítico y Capacidad de } \\
\text { síntesis }\end{array}$ & 3,299 & 3,966 & 3,556 & 3,908 \\
\hline Organización y Planificación & 3,364 & 4,313 & 3,294 & 4,216 \\
\hline $\begin{array}{l}\text { Comunicación oral y escrita en lengua } \\
\text { materna }\end{array}$ & 3,436 & 4,299 & 3,536 & 4,359 \\
\hline $\begin{array}{l}\text { Comunicación oral y escrita en lengua } \\
\text { extranjera }\end{array}$ & 2,093 & 4,254 & 2,275 & 4,183 \\
\hline Utilizar herramientas informáticas & 2,711 & 4,433 & 3,059 & 4,255 \\
\hline $\begin{array}{l}\text { Búsqueda de información en diversas } \\
\text { fuentes }\end{array}$ & 3,158 & 3,842 & 3,484 & 3,850 \\
\hline Resolución de conflictos o problemas & 2,866 & 4,203 & 2,797 & 4,065 \\
\hline Toma de decisiones & 2,983 & 4,371 & 2,778 & 4,176 \\
\hline Conocimientos de otras áreas o disciplinas & 2,814 & 3,533 & 2,693 & 3,353 \\
\hline Adquirir con rapidez nuevos conocimientos & 3,285 & 3,986 & 3,405 & 3,954 \\
\hline
\end{tabular}

Tabla 2. Valoración media del grado de preparación en la Universidad y la importancia en el trabajo. Primer bloque de competencias

Segundo bloque de competencias

Para el segundo bloque de competencias (tabla 3), respecto a la importancia en el trabajo, en general la media obtenida es superior a 3,7, llegando a la cota superior de 4,3 en el "uso del tiempo de forma efectiva", seguida con más de 4 en la "capacidad para hacerte entender", "trabajo en equipo multidisciplinar", "rendir bajo presión" y "relaciones personales y comunicación interpersonal". Mientras, en el grado de preparación, las medias oscilan entre el 2,3 de "trabajo en un contexto internacional", y el 3,4 de "rendir bajo presión" y el 3,2 de la "capacidad para hacerte entender" y el "trabajo en equipo de carácter multidisciplinar".

En la segmentación realizada por sexo la valoración media de los varones es siempre superior a la de sus compañeras las féminas, en todas las competencias y tanto cuando se refiere a la importancia en el trabajo como al grado de preparación en la 
Universidad. En la segmentación por experiencia profesional, como regla, para el total de alumnos la valoración media del grado de desarrollo en la Universidad de las competencias es mayor cuando tienen experiencia, y se detecta la misma regularidad respecto a la importancia en el trabajo, a excepción de la competencia "trabajar en un equipo de carácter multidisciplinar".

\begin{tabular}{|c|c|c|c|c|c|c|}
\hline \multirow{2}{*}{$\begin{array}{c}\text { Competencias } \\
\text { Segundo bloque }\end{array}$} & \multicolumn{3}{|c|}{$P U$} & \multicolumn{3}{|c|}{$I T$} \\
\hline & Varones & Mujeres & Todos & Varones & \multirow{2}{*}{$\begin{array}{c}\text { Mujeres } \\
4,112\end{array}$} & Todos \\
\hline Capacidad para hacerte entender & 3,327 & 3,076 & 3,200 & 4,350 & & 4,230 \\
\hline $\begin{array}{l}\text { Trabajar en equipo de carácter } \\
\text { multidisciplinar }\end{array}$ & 3,447 & 3,134 & 3,289 & 4,395 & 4,080 & 4,236 \\
\hline Trabajo en un Contexto internacional & 2,445 & 2,317 & 2,381 & 3,891 & 3,616 & 3,752 \\
\hline $\begin{array}{l}\text { Habilidad en relaciones personales y } \\
\text { Comunicación interpersonal }\end{array}$ & 3,109 & 2,893 & 3,000 & 4,245 & 3,933 & 4,088 \\
\hline $\begin{array}{l}\text { Trabajar en Entornos diversos y } \\
\text { multiculturales }\end{array}$ & 2,755 & 2,567 & 2,660 & 3,905 & 3,504 & 3,703 \\
\hline Capacidad Crítica y autocrítica & 3,014 & 2,946 & 2,980 & 4,014 & 3,688 & 3,849 \\
\hline Compromiso ético en el trabajo & 3,005 & 2,835 & 2,919 & 4,236 & 3,554 & 3,892 \\
\hline Rendir bajo presión & 3,505 & 3,375 & 3,439 & 4,182 & 4,179 & 4,180 \\
\hline Usar el tiempo de forma efectiva & 3,268 & 3,085 & 3,176 & 4,427 & 4,179 & 4,302 \\
\hline Aprendizaje autónomo & 3,555 & 3,545 & 3,550 & 4,041 & 3,696 & 3,867 \\
\hline \multirow{3}{*}{$\begin{array}{l}\text { Competencias } \\
\text { Segundo bloque }\end{array}$} & \multicolumn{3}{|c|}{$P U$} & \multicolumn{3}{|c|}{$I T$} \\
\hline & \multicolumn{3}{|c|}{ Experiencia laboral } & \multicolumn{3}{|c|}{ Experiencia laboral } \\
\hline & \multicolumn{2}{|l|}{$S I$} & NO & \multicolumn{2}{|l|}{$S I$} & NO \\
\hline Capacidad para hacerte entender & \multicolumn{2}{|c|}{3,260} & 3,169 & \multicolumn{2}{|l|}{4,253} & 4,217 \\
\hline $\begin{array}{l}\text { Trabajar en equipo de carácter } \\
\text { multidisciplinar }\end{array}$ & \multicolumn{2}{|c|}{3,314} & 3,276 & \multicolumn{2}{|l|}{4,182} & 4,266 \\
\hline Trabajo en un Contexto internacional & \multicolumn{2}{|c|}{2,526} & 2,303 & \multicolumn{2}{|l|}{3,877} & 3,686 \\
\hline $\begin{array}{l}\text { Habilidad en relaciones personales y } \\
\text { Comunicación interpersonal }\end{array}$ & \multicolumn{2}{|c|}{3,156} & 2,917 & \multicolumn{2}{|l|}{4,149} & 4,055 \\
\hline $\begin{array}{l}\text { Trabajar en Entornos diversos y } \\
\text { multiculturales }\end{array}$ & \multicolumn{2}{|c|}{2,903} & 2,531 & \multicolumn{2}{|l|}{3,792} & 3,655 \\
\hline Capacidad Crítica y autocrítica & \multicolumn{2}{|c|}{3,078} & 2,928 & \multicolumn{2}{|l|}{3,903} & 3,821 \\
\hline Compromiso ético en el trabajo & \multicolumn{2}{|c|}{3,045} & 2,852 & 3,994 & & 3,838 \\
\hline Rendir bajo presión & 3,53 & & 3,390 & 4,117 & & 4,214 \\
\hline Usar el tiempo de forma efectiva & 3,26 & & 3,128 & 4,325 & & 4,168 \\
\hline Aprendizaje autónomo & 3,50 & & 3,572 & 3,831 & & 4,290 \\
\hline
\end{tabular}




\begin{tabular}{|c|c|c|c|c|}
\hline \multirow{2}{*}{$\begin{array}{l}\text { Competencias } \\
\text { Segundo bloque }\end{array}$} & \multicolumn{2}{|c|}{4 curso } & \multicolumn{2}{|c|}{$5^{\circ}$ curso } \\
\hline & $P U$ & $I T$ & $P U$ & $I T$ \\
\hline Capacidad para hacerte entender & 3,224 & 4,278 & 3,169 & 4,164 \\
\hline $\begin{array}{l}\text { Trabajar en equipo de carácter } \\
\text { multidisciplinar }\end{array}$ & 3,310 & 4,298 & 3,261 & 4,153 \\
\hline Trabajo en un Contexto internacional & 2,365 & 3,780 & 2,402 & 3,714 \\
\hline $\begin{array}{l}\text { Habilidad en relaciones personales y } \\
\text { Comunicación interpersonal }\end{array}$ & 3,008 & 4,145 & 2,989 & 4,011 \\
\hline $\begin{array}{l}\text { Trabajar en Entornos diversos y } \\
\text { multiculturales }\end{array}$ & 2,620 & 3,686 & 2,714 & 3,725 \\
\hline Capacidad Crítica y autocrítica & 2,957 & 3,843 & 3,011 & 3,857 \\
\hline Compromiso ético en el trabajo & 2,898 & 3,910 & 2,947 & 3,868 \\
\hline Rendir bajo presión & 3,557 & 4,263 & 3,280 & 4,069 \\
\hline Usar el tiempo de forma efectiva & 3,122 & 4,349 & 3,249 & 4,238 \\
\hline Aprendizaje autónomo & 3,600 & 3,871 & 3,481 & 3,862 \\
\hline Competencias & \multicolumn{2}{|c|}{ ECO } & \multicolumn{2}{|c|}{$A D E$} \\
\hline Segundo bloque & $P U$ & $I T$ & $P U$ & $I T$ \\
\hline Capacidad para hacerte entender & 3,148 & 4,234 & 3,301 & 4,222 \\
\hline $\begin{array}{l}\text { Trabajar en equipo de carácter } \\
\text { multidisciplinar }\end{array}$ & 3,390 & 4,271 & 3,098 & 4,170 \\
\hline Trabajo en un Contexto internacional & 2,306 & 3,777 & 2,523 & 3,706 \\
\hline $\begin{array}{l}\text { Habilidad en relaciones personales y } \\
\text { Comunicación interpersonal }\end{array}$ & 2,986 & 4,137 & 3,026 & 3,993 \\
\hline $\begin{array}{l}\text { Trabajar en Entornos diversos y } \\
\text { multiculturales }\end{array}$ & 2,639 & 3,735 & 2,699 & 3,641 \\
\hline Capacidad Crítica y autocrítica & 2,993 & 3,904 & 2,954 & 3,745 \\
\hline Compromiso ético en el trabajo & 2,952 & 3,887 & 2,856 & 3,902 \\
\hline Rendir bajo presión & 3,460 & 4,237 & 3,399 & 4,072 \\
\hline Usar el tiempo de forma efectiva & 3,189 & 4,320 & 3,150 & 4,268 \\
\hline Aprendizaje autónomo & 3,553 & 3,876 & 3,542 & 3,850 \\
\hline
\end{tabular}

Tabla 3. Valoración media del grado de preparación en la Universidad y la importancia en el trabajo. Segundo bloque de competencias

\section{Tercer bloque de competencias}

En cuanto a los valores medios, que se presentan en la tabla 4 tanto para el total de encuestados como las segmentaciones, y respecto a la importancia en el trabajo, en general la media obtenida es superior al 3,2 de "sensibilidad medioambiental", llegando a la cota superior de 4,30 de "aplicación de conocimientos a la práctica", seguida del 4,16, en la "adaptación a nuevas situaciones" e "iniciativa y espíritu emprendedor" y el 4,08 de" liderazgo". Mientras, respecto al grado de preparación, las medias oscilan entre el 2,3 de "sensibilidad medioambiental", y el 3,2 de "búsqueda de información e investigación”. 
Según la información segmentada por submuestras, en general la valoración media de los varones es ligeramente superior a la de sus compañeras las féminas, en todas las competencias cuando se refiere a la importancia en el trabajo, y con la excepción de "capacidad para divulgar las cuestiones económicas" y "orientación al logro" en lo que respecta al grado de preparación en la Universidad. Además, como regla, para el total de alumnos la valoración media del grado de desarrollo o preparación en la Universidad de las competencias es mayor cuando tienen experiencia, regularidad que también se observa en el caso de la importancia en el trabajo, a excepción de "motivación por la calidad", "aplicar conocimientos a la práctica" y "búsqueda de información e investigación".

\begin{tabular}{|c|c|c|c|c|c|c|}
\hline \multirow{2}{*}{$\begin{array}{l}\text { Competencias } \\
\text { Tercer bloque }\end{array}$} & \multicolumn{3}{|c|}{$P U$} & \multicolumn{3}{|c|}{$I T$} \\
\hline & Varones & Mujeres & Todos & Varones & Mujeres & Todos \\
\hline Adaptación a nuevas situaciones & 3,168 & 3,031 & 3,099 & 4,336 & 3,996 & 4,164 \\
\hline Creatividad & 2,859 & 2,625 & 2,741 & 4,064 & 3,723 & 3,892 \\
\hline Liderazgo & 2,723 & 2,571 & 2,646 & 4,091 & 4,076 & 4,083 \\
\hline $\begin{array}{l}\text { Iniciativa y espíritu emprendedor : encontrar } \\
\text { nuevas ideas y soluciones }\end{array}$ & 2,864 & 2,795 & 2,829 & 4,332 & 4,009 & 4,169 \\
\hline Motivación por la calidad & 2,968 & 2,964 & 2,966 & 3,941 & 3,911 & 3,926 \\
\hline Sensibilidad medioambiental & 2,336 & 2,304 & 2,320 & 3,432 & 2,973 & 3,200 \\
\hline Sensibilidad temas sociales & 2,709 & 2,652 & 2,680 & 3,755 & 3,098 & 3,423 \\
\hline Aplicar los conocimientos a la práctica & 3,273 & 2,969 & 3,119 & 4,518 & 4,098 & 4,306 \\
\hline $\begin{array}{l}\text { Habilidad de búsqueda de información e } \\
\text { investigación }\end{array}$ & 3,214 & 3,201 & 3,207 & 4,136 & 3,665 & 3,899 \\
\hline Diseño y gestión de proyectos & 2,864 & 2,835 & 2,849 & 4,068 & 3,781 & 3,923 \\
\hline \multirow{3}{*}{$\begin{array}{l}\text { Competencias } \\
\text { Tercer bloque }\end{array}$} & \multicolumn{3}{|c|}{$P U$} & \multicolumn{3}{|c|}{$I T$} \\
\hline & \multicolumn{3}{|c|}{ Experiencia laboral } & \multicolumn{3}{|c|}{ Experiencia laboral } \\
\hline & \multicolumn{2}{|c|}{$S I$} & NO & $S I$ & & NO \\
\hline Adaptación a nuevas situaciones & \multicolumn{2}{|c|}{3,149} & 3,072 & \multicolumn{2}{|l|}{4,201} & 4,145 \\
\hline Creatividad & \multicolumn{2}{|c|}{2,838} & 2,690 & \multicolumn{2}{|l|}{3,981} & 3,845 \\
\hline Liderazgo & \multicolumn{2}{|c|}{2,727} & 2,603 & \multicolumn{2}{|l|}{4,123} & 4,062 \\
\hline $\begin{array}{l}\text { Iniciativa y espíritu emprendedor : encontrar } \\
\text { nuevas ideas y soluciones }\end{array}$ & \multicolumn{2}{|c|}{2,916} & 2,783 & \multicolumn{2}{|l|}{4,240} & 4,131 \\
\hline Motivación por la calidad & \multicolumn{2}{|c|}{3,039} & 2,928 & \multicolumn{2}{|l|}{3,870} & 3,955 \\
\hline Sensibilidad medioambiental & \multicolumn{2}{|c|}{2,403} & 2,276 & \multicolumn{2}{|l|}{3,318} & 3,138 \\
\hline Sensibilidad temas sociales & \multicolumn{2}{|c|}{2,831} & 2,600 & \multicolumn{2}{|l|}{3,623} & 3,317 \\
\hline Aplicar los conocimientos a la práctica & 3,24 & & 3,055 & 4,279 & & 4,321 \\
\hline $\begin{array}{l}\text { Habilidad de búsqueda de información e } \\
\text { investigación }\end{array}$ & 3,20 & & 3,207 & 3,896 & & 3,900 \\
\hline Diseño y gestión de proyectos & 2,92 & & 2,807 & 3,955 & & 3,907 \\
\hline
\end{tabular}




\begin{tabular}{|c|c|c|c|c|}
\hline \multirow{2}{*}{$\begin{array}{l}\text { Competencias } \\
\text { Tercer bloque }\end{array}$} & \multicolumn{2}{|c|}{4 curso } & \multicolumn{2}{|c|}{$5^{\circ}$ curso } \\
\hline & $P U$ & $I T$ & $P U$ & $I T$ \\
\hline Adaptación a nuevas situaciones & 3,098 & $\overline{4,192}$ & 3,101 & $\overline{4,127}$ \\
\hline Creatividad & 2,804 & 3,878 & 2,656 & 3,910 \\
\hline Liderazgo & 2,639 & 4,043 & 2,656 & 4,138 \\
\hline $\begin{array}{l}\text { Iniciativa y espíritu emprendedor : encontrar } \\
\text { nuevas ideas y soluciones }\end{array}$ & 2,859 & 4,165 & 2,788 & 4,175 \\
\hline Motivación por la calidad & 2,980 & 3,988 & 2,947 & 3,841 \\
\hline Sensibilidad medioambiental & 2,329 & 3,216 & 2,307 & 3,180 \\
\hline Sensibilidad temas sociales & 2,722 & 3,400 & 2,624 & 3,455 \\
\hline Aplicar los conocimientos a la práctica & 3,125 & 4,271 & 3,111 & 4,354 \\
\hline $\begin{array}{l}\text { Habilidad de búsqueda de información e } \\
\text { investigación }\end{array}$ & 3,200 & 3,906 & 3,217 & 3,889 \\
\hline Diseño y gestión de proyectos & 2,839 & 3,965 & 2,862 & 3,868 \\
\hline \multirow{2}{*}{$\begin{array}{l}\text { Competencias } \\
\text { Tercer bloque }\end{array}$} & \multicolumn{2}{|c|}{$E C O$} & \multicolumn{2}{|c|}{$A D E$} \\
\hline & $P U$ & $I T$ & $P U$ & $I T$ \\
\hline Adaptación a nuevas situaciones & 3,093 & 4,213 & 3,111 & 4,072 \\
\hline Creatividad & 2,801 & 3,962 & 2,627 & 3,758 \\
\hline Liderazgo & 2,715 & 4,148 & 2,516 & 3,961 \\
\hline $\begin{array}{l}\text { Iniciativa y espíritu emprendedor : encontrar } \\
\text { nuevas ideas y soluciones }\end{array}$ & 2,863 & 4,192 & 2,765 & 4,124 \\
\hline Motivación por la calidad & 2,938 & 3,911 & 3,020 & 3,954 \\
\hline Sensibilidad medioambiental & 2,296 & 3,237 & 2,366 & 3,131 \\
\hline Sensibilidad temas sociales & 2,601 & 3,443 & 2,830 & 3,386 \\
\hline Aplicar los conocimientos a la práctica & 3,141 & 4,378 & 3,078 & 4,170 \\
\hline $\begin{array}{l}\text { Habilidad de búsqueda de información e } \\
\text { investigación }\end{array}$ & 3,168 & 3,945 & 3,281 & 3,810 \\
\hline Diseño y gestión de proyectos & 2,900 & 3,962 & 2,752 & 3,850 \\
\hline
\end{tabular}

Tabla 4. Media de la valoración del grado de preparación en la Universidad y la importancia en el trabajo. Tercer bloque de competencias

\section{Cuarto bloque de competencias}

El cuarto y último bloque de competencias que se presenta (tabla 5) muestra que, respecto a la importancia en el trabajo, la media obtenida es superior al 3,59 de "autoevaluación emocional", llegando a la cota superior de 4,2, en "redactar informes o documentos", "confianza en uno mismo" y "expresar ideas y defender derechos sin agredir". Mientras, atendiendo al grado de preparación, las medias oscilan entre el 2,46 de "negociación eficaz", y el 3,33 de "expresar ideas y defender derechos sin agredir".

Segmentando la información por submuestras, cabe destacar que, en general, la valoración media de los varones es ligeramente superior a la de sus compañeras las féminas, en todas las competencias cuando se refiere a la importancia en el trabajo, y con la excepción de "negociar de forma eficaz" y "la orientación al logro" en lo que respecta al grado de preparación en la Universidad. Como regla y para el total de alumnos la valoración media, tanto del grado de desarrollo en la Universidad de las 
competencias como de la importancia en el trabajo, es mayor cuando los estudiantes aportan experiencia previa y solo destaca la excepción de "redactar informes o documento" y "la orientación al logro", ésta última referida a la importancia en el entorno laboral.

\begin{tabular}{|c|c|c|c|c|c|c|}
\hline \multirow{2}{*}{$\begin{array}{l}\text { Competencias } \\
\text { Cuarto bloque }\end{array}$} & \multicolumn{3}{|c|}{$P U$} & \multicolumn{3}{|c|}{$I T$} \\
\hline & Varones & Mujeres & Todos & Varones & Mujeres & Todos \\
\hline $\begin{array}{l}\text { Capacidad para divulgación de cuestiones } \\
\text { económicas }\end{array}$ & 2,909 & 3,045 & 2,977 & 3,836 & 3,558 & 3,696 \\
\hline $\begin{array}{l}\text { Presentar en público productos, ideas o } \\
\text { informes }\end{array}$ & 3,336 & 3,228 & 3,282 & 4,309 & 4,027 & 4,167 \\
\hline Negociar de forma eficaz & 2,659 & 2,263 & 2,459 & 4,273 & 4,054 & 4,162 \\
\hline Redactar informes o documentos & 3,227 & 3,125 & 3,176 & 4,382 & 4,031 & 4,205 \\
\hline Autoconciencia emocional & 2,686 & 2,589 & 2,637 & 3,850 & 3,366 & 3,606 \\
\hline Autoevaluación emocional & 2,714 & 2,571 & 2,642 & 3,818 & 3,375 & 3,595 \\
\hline Confianza en uno mismo & 2,945 & 2,915 & 2,930 & 4,414 & 4,085 & 4,248 \\
\hline Empatía & 2,864 & 2,835 & 2,849 & 4,045 & 3,638 & 3,840 \\
\hline Orientación al logro & 3,145 & 3,192 & 3,169 & 4,264 & 4,004 & 4,133 \\
\hline Expresar ideas y defender derechos sin agredir & 3,377 & 3,286 & 3,331 & 4,414 & \multirow{2}{*}{$\begin{array}{c}4,089 \\
I T\end{array}$} & 4,250 \\
\hline \multirow{3}{*}{$\begin{array}{l}\text { Competencias } \\
\text { Cuarto bloque }\end{array}$} & \multicolumn{3}{|c|}{$P U$} & \multirow{2}{*}{\multicolumn{3}{|c|}{$\frac{I T}{\text { Experiencia laboral }}$}} \\
\hline & \multicolumn{3}{|c|}{ Experiencia laboral } & & & \\
\hline & \multicolumn{2}{|l|}{ SI } & NO & \multicolumn{3}{|c|}{\begin{tabular}{|l|l} 
SI & NO \\
\end{tabular}} \\
\hline $\begin{array}{l}\text { Capacidad para divulgación de cuestiones } \\
\text { económicas }\end{array}$ & \multicolumn{2}{|c|}{3,078} & 2,924 & 3,740 & \multicolumn{2}{|c|}{3,672} \\
\hline $\begin{array}{l}\text { Presentar en público productos, ideas o } \\
\text { informes }\end{array}$ & 3,32 & & 3,259 & 4,221 & & \\
\hline Negociar de forma eficaz & 2,56 & & 2,403 & 4,195 & & \\
\hline Redactar informes o documentos & 3,16 & & 3,179 & 4,175 & & \\
\hline Autoconciencia emocional & 2,78 & & 2,559 & 3,656 & & \\
\hline Autoevaluación emocional & 2,838 & & 2,538 & 3,623 & & \\
\hline Confianza en uno mismo & 3,07 & & 2,855 & 4,286 & & 28 \\
\hline Empatía & 2,929 & & 2,807 & 3,857 & & \\
\hline Orientación al logro & 3,17 & & 3,166 & 4,071 & & 66 \\
\hline Expresar ideas y defender derechos sin agredir & 3,558 & & 3,210 & 4,344 & & 00 \\
\hline
\end{tabular}

\begin{tabular}{|l|c|c|c|c|}
\hline \multicolumn{1}{|c|}{$\begin{array}{c}\text { Competencias } \\
\text { Cuarto bloque }\end{array}$} & \multicolumn{2}{c|}{$\mathbf{4}^{\circ}$ curso } & \multicolumn{2}{c|}{$\mathbf{5}^{\circ}$ curso } \\
\cline { 2 - 5 } & PU & IT & PU & IT \\
\hline $\begin{array}{l}\text { Capacidad para divulgación de cuestiones } \\
\text { económicas }\end{array}$ & 2,961 & 3,682 & 3,000 & 3,714 \\
\hline $\begin{array}{l}\text { Presentar en público productos, ideas o } \\
\text { informes }\end{array}$ & 3,373 & 4,165 & 3,159 & 4,169 \\
\hline Negociar de forma eficaz & 2,467 & 4,157 & 2,450 & 4,169 \\
\hline Redactar informes o documentos & 3,259 & 4,227 & 3,063 & 4,175 \\
\hline Autoconciencia emocional & 2,671 & 3,600 & 2,593 & 3,614 \\
\hline
\end{tabular}




\begin{tabular}{|c|c|c|c|c|}
\hline Autoevaluación emocional & 2,635 & 3,600 & 2,651 & 3,587 \\
\hline Confianza en uno mismo & 2,898 & 4,286 & 2,974 & 4,196 \\
\hline Empatía & 2,847 & 3,878 & 2,852 & 3,788 \\
\hline Orientación al logro & 3,161 & 4,192 & 3,180 & 4,053 \\
\hline Expresar ideas y defender derechos sin agredir & 3,322 & 4,247 & 3,344 & 4,254 \\
\hline \multirow{2}{*}{$\begin{array}{l}\text { Competencias } \\
\text { Cuarto bloque }\end{array}$} & \multicolumn{2}{|c|}{ ECO } & \multicolumn{2}{|c|}{$A D E$} \\
\hline & $P U$ & IT & $P U$ & $I T$ \\
\hline $\begin{array}{l}\text { Capacidad para divulgación de cuestiones } \\
\text { económicas }\end{array}$ & 2,890 & 3,660 & 3,144 & 3,765 \\
\hline $\begin{array}{l}\text { Presentar en público productos, ideas o } \\
\text { informes }\end{array}$ & 3,381 & 4,220 & 3,092 & 4,065 \\
\hline Negociar de forma eficaz & 2,481 & 4,168 & 2,418 & 4,150 \\
\hline Redactar informes o documentos & 3,134 & 4,216 & 3,255 & 4,183 \\
\hline Autoconciencia emocional & 2,680 & 3,622 & 2,556 & 3,575 \\
\hline Autoevaluación emocional & 2,660 & 3,601 & 2,608 & 3,582 \\
\hline Confianza en uno mismo & 2,931 & 4,296 & 2,928 & 4,157 \\
\hline Empatía & 2,869 & 3,838 & 2,810 & 3,843 \\
\hline Orientación al logro & 3,189 & 4,179 & 3,131 & 4,046 \\
\hline Expresar ideas y defender derechos sin agredir & 3,313 & 4,289 & 3,366 & 4,176 \\
\hline
\end{tabular}

Tabla 5. Media de la valoración del grado de preparación en la Universidad y la importancia en el trabajo. Cuarto bloque de competencias

Para finalizar esta descripción, cabe señalar que se han analizado los gráficos de distribución de respuestas o histogramas y los gráficos de dispersión de respuestas, si bien no se presentan en el texto, para facilitar su lectura. Los primeros reflejan que las variables referidas a la formación universitaria ( PU) no presentan en general un patrón uniforme, dado que definen todo tipo de casuística, desde distribuciones con asimetría negativa (mayor dispersión y cola a la izquierda y mayor concentración a la derecha) o positiva y cargando las respuestas a la izquierda. Por el contrario, en cuanto a la pregunta sobre el grado de importancia en el entorno laboral (IT), en general se observa una mayor regularidad hacia distribuciones con asimetría negativa, con mayor cola a la izquierda y mayor acumulación de las respuestas a la derecha. Los gráficos de dispersión de respuestas por competencia, en general muestran una relación positiva, según la cual el mayor grado de desarrollo en la formación se acompaña de una mayor importancia en el entorno laboral, pero por debajo de la bisectriz, hecho que denota el menor diferencial en la acumulación de respuestas por tramos de valoración.

Tanto en el análisis descriptivo previo, como en la extracción de los factores principales que se presenta en el siguiente apartado, se ha considerado conjuntamente las submuestras de ambos centros, UCM y UAH, dado que tanto con el test de Levene como la prueba $\mathrm{T}$ para muestras independientes, han contrastado que se acepta la hipótesis de igualdad de varianzas, pudiendo ser estudiadas en una misma muestra. 


\section{Identificación de los factores explicativos}

\section{Matriz de correlaciones y adecuación del análisis factorial}

El análisis factorial permite explicar un conjunto de variables observables mediante un número reducido de variables no observables o latentes, denominadas factores, configurados por agrupación de varias de ellas, de forma que las variables que conforman cada factor estén altamente correlacionadas, mientras que los grupos estén incorrelacionados entre sí.

En este ejercicio exploratorio el análisis factorial se realiza simétricamente tanto para las preguntas referidas al grado de desarrollo de competencias asociado a la preparación en la Universidad (_PU) como a la importancia que los estudiantes creen que tiene en el entorno laboral ( IT). Dada la amplitud de la matriz de variables analizadas, y para facilitar la lectura del texto, los datos se presentan de forma paralela en el anexo 1 y 2 para las preguntas (_PU) e ( IT) respectivamente. Un guía clara y secuencial de ésta técnica analítica se puede encontrar en el manual de Vinacua ${ }^{5}$ (1998) y en el interesante trabajo de Balbuena y Casas (2003).

La muestra de datos (444 individuos, 40 competencias y 3 variables dummy) cumple con las orientaciones estándares que proponen que la muestra de individuos analizada, N, tenga más de 100 sujetos (Kline, 1994) y sea 10 veces mayor que el número de variables o ítems, $\mathrm{K},(\mathrm{N}=10 \mathrm{~K})$, según expusieron Nunnally (1978) y ThorndiKe (1982), para encontrar una estructura factorial ${ }^{6}$ clara.

El estudio de las matrices de correlación de todas las variables analizadas, competencias y dummys de segmentación, muestra, a partir del determinante de dicha matriz que toma valor cercano a cero, $\left(\mathrm{D}_{-} \mathrm{PU}=5,19 \mathrm{E}-010\right.$ y $\mathrm{D}_{\mathrm{IT}}=6,77 \mathrm{E}-008$, respectivamente en las matrices_PU e_IT), que las variables están claramente correlacionadas. El valor de dichos determinantes, junto con los índices Kaiser-Meyer-Olkin (KMO) y los contrastes de esfericidad de Barlett (que se muestran a continuación en la tabla 6), refuerzan la pertinencia del análisis factorial que se desarrolla, al ser ambas pruebas indicadores de la magnitud de la relación lineal entre las variables. Así, dado que el KMO $>0,93$ en ambos casos, y la prueba de esfericidad determina un valor Chi-cuadrado $\left(\chi^{2}\right)$ muy alto y significación nula, se rechaza la hipótesis de que la matriz de correlaciones sea la identidad. Además, y como es de esperar, las matrices de covarianzas y correlaciones anti-imagen muestran en la diagonal valores altos mientras que para el resto de pares de variables son bajos ${ }^{7}$.

\footnotetext{
${ }^{5}$ El análisis estadístico se ha realizado con SPSS.

${ }^{6}$ Una estructura clara es aquella en que ninguna variable define simultáneamente más de un factor y cada factor tiene más de una variable.

${ }^{7}$ Se ha optado por no presentar en el anexo estas tablas dada su extensión, toda vez que las pruebas KMO y Barlett lo confirman.
} 


\begin{tabular}{|c|c|c|c|c|c|}
\hline \multicolumn{3}{|c|}{ Preparación en la Universidad ( $P U)$} & \multicolumn{3}{|c|}{ Importancia en el trabajo (IT) } \\
\hline \multicolumn{2}{|c|}{ Adecuación muestral KMO } & ,951 & \multicolumn{2}{|c|}{ Adecuación muestral KMO } & ,930 \\
\hline \multirow{3}{*}{$\begin{array}{c}\text { Prueba de } \\
\text { Bartlett }\end{array}$} & $\chi^{2}$ aproximado & 912 & \multirow{3}{*}{$\begin{array}{c}\text { Prueba de } \\
\text { Bartlett }\end{array}$} & $\chi^{2}$ aproximado & 7062,562 \\
\hline & $\mathrm{Gl}$ & 903 & & $\mathrm{Gl}$ & 90 \\
\hline & Sig. &, 000 & & Sig. & 000 \\
\hline
\end{tabular}

Tabla 6. Medida de adecuación muestral de Kaiser-Meyer-Olkin (KMO) y prueba de esfericidad de Bartlett

\section{Extracción de factores, rotación y estudio de las puntuaciones}

Las comunalidades asignadas a la extracción factorial, tablas 1.1 y 2.1 de los anexos 1 y 2 , muestran la proporción de la varianza que puede ser explicada con el análisis factorial que se presenta. Así, en negrita se han señalado las variables mejor y peor explicadas con el modelo, en éste último caso sombreadas, con valores superiores a 0,7 y a 0,4 respectivamente. En concreto, en la pregunta de preparación de la Universi$\boldsymbol{d a d}$, las variables mejor explicadas son "autoevaluación emocional" y "sensibilidad por los temas sociales", con el 73,8 y el 71,1\% de su variabilidad original explicada, respectivamente. En el extremo opuesto, las competencias peor explicadas son "trabajar en equipo de carácter multidisciplinar", para la cual el modelo es capaz de explicar el $43,1 \%$ de su variabilidad original, seguida de "conocimiento de otras áreas o disciplinas", "redactar informes o documentos" y "compromiso ético con el trabajo", con porcentajes que oscilan entre el 45,9 y el $48,2 \%$.

En la pregunta referida a la importancia en el entorno laboral, las competencias mejor explicadas son "autoevaluación emocional" y "autoconciencia emocional", con el $77 \%$ de su variabilidad original explicada, seguidas de "sensibilidad por los temas sociales" con el $74,6 \%$, mientras que las competencias peor explicadas son "autoaprendizaje autónomo" con solo el $41,9 \%$ de su variabilidad original explicada, seguida de "capacidad crítica y autocrítica", "trabajar en equipo multidisciplinar" y "adquirir con rapidez nuevos conocimientos", con porcentajes que oscilan entre el 46,6 y el $47,7 \%$.

En el proceso de extracción de factores explicativos, tal como muestran las tablas 1.2 y 2.2 , de los anexos 1 y 2 respectivamente, los resultados en ambas preguntas son muy parecidos. Así, en la matriz PU solo se identifican 9 factores o componentes con un valor propio inicial superior a $\overline{1}$, que llegan a explicar conjuntamente el $59,6 \%$ de la varianza y solo el primero de ellos el $35,146 \%$ de la misma. En cuanto a la matriz _IT, se identifican 10 factores, que si bien conjuntamente llegan a explicar el 57,22\%, son más inestables, puesto que el primero de ellos solo explica el 28,45\%. Estos porcentajes de varianza total explicada, relativamente bajos, pueden indicar que, o bien hay otras variables no recogidas en la encuesta que podrían contribuir a la explicación, o hay confusión en la interpretación de las mismas por parte de los encuestados. 
La rotación de los factores permite interpretar los factores extraídos, para lo cual nos centramos en el análisis de la matriz de componentes rotados con procedimiento ortogonales ${ }^{8}$ Varimax, para cada una de las preguntas analizadas (tablas 1.3 y 2.3 de los anexos 1 y 2 respectivamente), señaladas con sombreado gris las relaciones positivas entre factores y variables, y en azul las negativas. La determinación del número de factores extraídos, dado el método de rotación seguido (criterio de Kaiser, que rota los factores que previamente tienen una varianza o "autovalor o eigenvalue" mayor que 1) determina, quizás, un número excesivo de factores ${ }^{9}$.

Gráfico 1. Sedimentación

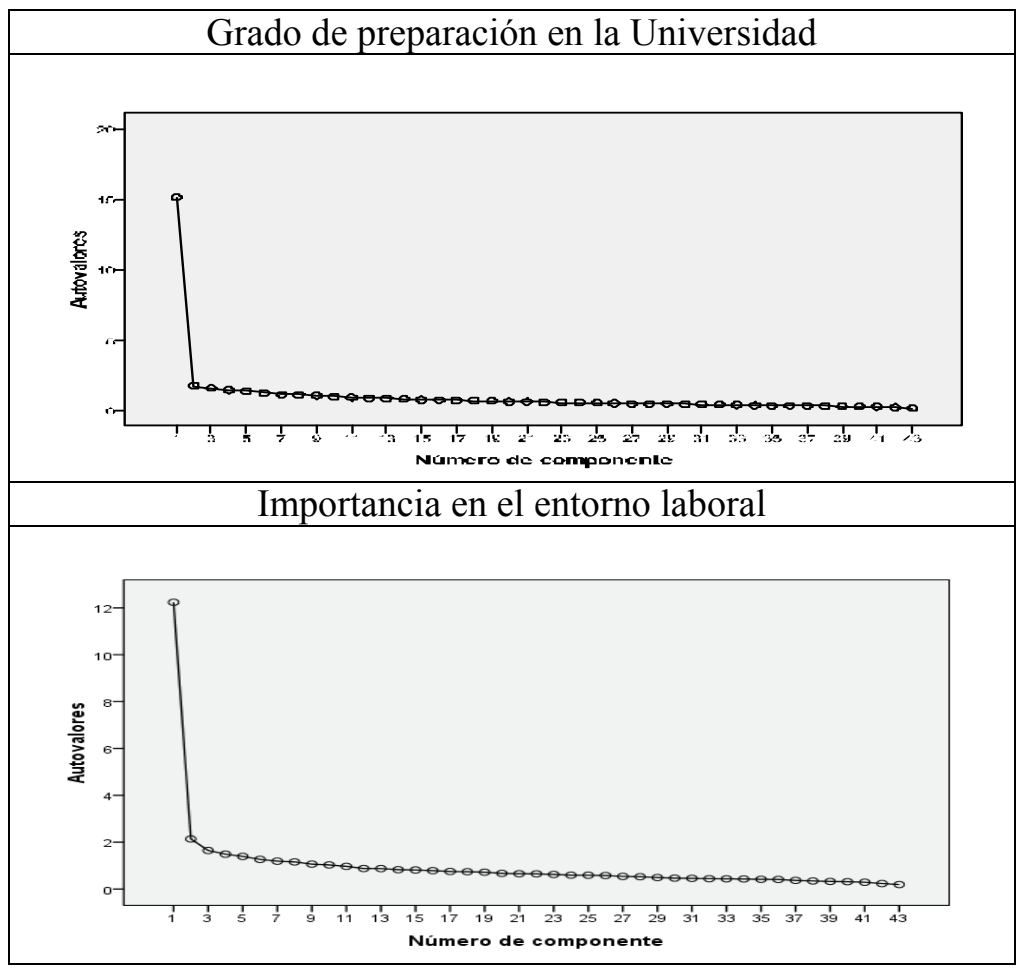

Este resultado se confirma en los gráficos de sedimentación adjuntos, donde en abscisas se muestran el total de componentes (variables) y en ordenadas el valor propio o

${ }^{8}$ La rotación ortogonal Varimax determina factores cuyas puntuaciones factoriales no están relacionadas con los demás, y tienen como ventaja una interpretación más sencilla. Determina una matriz de correlaciones de cada variable con cada factor (factor structure) y los pesos para calcular las puntuaciones factoriales (pattern structure).

${ }^{9}$ Una buena guía del procedimiento e interpretación del análisis factorial se encuentra en Morales (2010), que remite, con un buen criterio, a la revisión de trabajos realizada por Henson y Roberts (2006), quienes encuentran que casi el 57\% de los trabajos utilizan el criterio de Kaiser, y el resto el gráfico de sedimentación o "scree test". 
varianza explicada. Se observa que los factores con un autovalor mayor que 1 son, como ya se había señalado, 9 en la matriz_PU y 10 en la matriz _IT, si bien a partir del factor 2 en ambos casos hay una clara inflexión en la pendiente de ambos gráficos, y si bien aportan una menor varianza total explicada, como es lógico, determinan una estructura factorial más claramente identificada que favorece la interpretación, hecho que puede ser tenido en cuenta en la realización de un futuro análisis confirmatorio.

Destacar que, siguiendo el criterio estándar para muestras superiores a 300 individuos, la estructura de componentes obtenida define bien los factores, dado que los pesos son superiores a 0,35 , con la cota superior de 0,84 , en la matriz _PU y con valores en el rango entre 0,32 y 0,75 en la matriz _IT.

En cuanto a los signos obtenidos, en la pregunta_PU las variables con coeficiente negativo corresponden únicamente al "sexo" y a la "experiencia laboral", siendo positivo el curso, mientras que en la pregunta_IT la relación de signos en estas tres variables es la inversa.

En general no hay una total coincidencia en cuanto a las capacidades o variables que se agrupan en los factores/componentes seleccionados, tal como muestran los cuadros 1 y 2. Unicamente en la matriz _PU uno de los factores está determinado por una única variable, el sexo, sin interrelacionarse con los demás factores. Así, si denominamos factores "sólidos" a los definidos por 5 o más ítems con pesos superiores a 0,30 , tendríamos identificados los cuatro primeros factores, tanto en la matriz PU, como en la IT, y "medio sólidos" a los que tienen entre 3 y 5, en la matriz_PU tendríamos los factores 5 y 6 y en la_IT los factores 5, 6 y 7 . El resto de factores obtenidos serían inestables en la estructura del constructo analizado. Para su identificación se ha utilizado la gama de grises, más intensa a mayor grado de solidez, tal como se muestra en los cuadros siguientes. En un intento por conceptualizar los factores extraídos, en la matriz PU los factores sólidos se definen como "motivación personal, motivación por el trabajo y su entorno", "habilidad para el desempeño laboral" y "adaptabilidad social", siéndolos medio sólidos "autogestión práctica" y "habilidad comunicativa", mientras que en la matriz IT los factores extraídos y sus componentes difieren, definiéndose los sólidos como "hābilidad para generar oportunidades", "habilidades de gestión eficaz", "motivación por el éxito profesional" y "aprendizaje efectivo y multidisciplinar", quedando como medio sólidos "las habilidades asertivas", la "motivación por la comunicación eficiente" y la "habilidad de adaptabilidad", tal como puede verse a continuación con el detalle de las variables que se agrupan en dichos factores. 


\begin{tabular}{|c|c|c|}
\hline \multicolumn{2}{|c|}{ Factor/componente } & Variables \\
\hline \multirow{4}{*}{ Sólido } & $\begin{array}{c}1 \\
\text { Motivación } \\
\text { personal }\end{array}$ & $\begin{array}{l}\text { Autoevaluación emocional } \\
\text { Orientación al logro } \\
\text { Autoconciencia emocional } \\
\text { Confianza en uno mismo } \\
\text { Empatía } \\
\text { Expresar ideas y defender derechos sin agredir } \\
\text { Usar el tiempo de forma efectiva }\end{array}$ \\
\hline & $\begin{array}{c}2 \\
\text { Motivación por } \\
\text { el trabajo y su } \\
\text { entorno }\end{array}$ & $\begin{array}{l}\text { Sensibilidad medioambiental } \\
\text { Sensibilidad temas sociales } \\
\text { Trabajo en un contexto internacional } \\
\text { Creatividad } \\
\text { Trabajar en entornos diversos y multiculturales } \\
\text { Iniciativa y espíritu emprendedor } \\
\text { Liderazgo } \\
\text { Compromiso ético en el trabajo } \\
\text { Capacidad para la divulgación de las cuestiones } \\
\text { económicas } \\
\text { Conocimientos de otras áreas o disciplinas }\end{array}$ \\
\hline & $\begin{array}{c}3 \\
\text { Habilidad para } \\
\text { el desempeño } \\
\text { laboral }\end{array}$ & $\begin{array}{l}\text { Motivación por la calidad } \\
\text { Capacidad de utilizar herramientas informáticas } \\
\text { Comunicación oral y escrita en lengua extranjera } \\
\text { Resolución de conflictos o problemas } \\
\text { Comunicación oral y escrita en lengua materna } \\
\text { Habilidad para búsqueda de información en diversas } \\
\text { fuentes } \\
\text { Toma de decisiones } \\
\text { Trabajar en equipo de carácter multidisciplinar }\end{array}$ \\
\hline & $\begin{array}{c}4 \\
\begin{array}{c}\text { Adaptabilidad } \\
\text { social }\end{array}\end{array}$ & $\begin{array}{l}\text { Rendir bajo presión } \\
\text { Adaptación a nuevas situaciones } \\
\text { Habilidad en relaciones personales } \\
\text { Capacidad crítica y autocrítica } \\
\text { Capacidad para hacerte entender }\end{array}$ \\
\hline
\end{tabular}




\begin{tabular}{|c|c|l|}
\hline \multirow{4}{*}{$\begin{array}{c}\text { Medio } \\
\text { sólido }\end{array}$} & $\begin{array}{c}\mathbf{5} \\
\text { Autogestión } \\
\text { práctica }\end{array}$ & $\begin{array}{l}\text { Aprendizaje autónomo } \\
\text { Habilidad de búsqueda de información e investiga- } \\
\text { ción } \\
\text { Aplicar los conocimientos a la práctica; Adquirir con } \\
\text { rapidez nuevos conocimientos }\end{array}$ \\
\cline { 2 - 3 } & $\begin{array}{c}\mathbf{6} \\
\text { Habilidad co- } \\
\text { municativa }\end{array}$ & $\begin{array}{l}\text { Presentar en público productos ideas o informes } \\
\text { Diseño y gestión de proyectos } \\
\text { Negociar de forma eficaz } \\
\text { Redactar informes o documentos }\end{array}$ \\
\hline \multirow{2}{*}{$\begin{array}{c}\text { Poco } \\
\text { sólido }\end{array}$} & $\mathbf{7}$ & $\begin{array}{l}\text { Pensamiento analítico y capacidad de síntesis } \\
\text { Organización y planificación }\end{array}$ \\
\cline { 2 - 3 } & $\mathbf{8}$ & Sexo \\
\hline
\end{tabular}

Cuadro 1. Resumen de las variables que explican o se agrupan en los factores_PU

\begin{tabular}{|c|c|c|}
\hline \multicolumn{2}{|c|}{ Factor/componente } & Variables \\
\hline \multirow{4}{*}{ Sólido } & $\begin{array}{c}1 \\
\text { Habilidad para } \\
\text { generar opor- } \\
\text { tunidades }\end{array}$ & $\begin{array}{l}\text { Compromiso ético en el trabajo } \\
\text { Presentar en público productos ideas o informes } \\
\text { Iniciativa y espíritu emprendedor IT } \\
\text { Toma de decisiones } \\
\text { Creatividad } \\
\text { Resolución de conflictos o problemas }\end{array}$ \\
\hline & $\begin{array}{c}2 \\
\text { Habilidades de } \\
\text { gestión eficaz }\end{array}$ & $\begin{array}{l}\text { Trabajar en entornos diversos y multiculturales } \\
\text { Diseño y gestión de proyectos } \\
\text { Adaptación a nuevas situaciones } \\
\text { Autoconciencia emocional } \\
\text { Negociar de forma eficaz } \\
\text { Relaciones personales }\end{array}$ \\
\hline & \begin{tabular}{c}
\multicolumn{1}{c}{3} \\
Motivación \\
por el éxito \\
profesional
\end{tabular} & $\begin{array}{l}\text { Orientación al logro } \\
\text { Trabajar en equipo de carácter multidisciplinar } \\
\text { Redactar informes o documentos IT } \\
\text { Confianza en uno mismo } \\
\text { Capacidad crítica y autocrítica } \\
\text { Búsqueda de información e investigación } \\
\text { Autoevaluación emocional }\end{array}$ \\
\hline & $\begin{array}{c}4 \\
\text { Aprendizaje } \\
\text { efectivo y mul- } \\
\text { tidisciplinar }\end{array}$ & $\begin{array}{l}\text { Divulgación de las cuestiones económicas } \\
\text { Trabajo en un contexto internacional } \\
\text { Conocimientos de otras áreas o disciplinas } \\
\text { Adquirir con rapidez nuevos conocimientos } \\
\text { Aprendizaje autónomo } \\
\text { Usar el tiempo de forma efectiva } \\
\text { Organización y planificación }\end{array}$ \\
\hline
\end{tabular}




\begin{tabular}{|c|c|c|}
\hline \multirow{3}{*}{$\begin{array}{l}\text { Medio } \\
\text { sólido }\end{array}$} & $\begin{array}{l}5 \\
\text { Habilidades } \\
\text { asertivas }\end{array}$ & $\begin{array}{l}\text { Aplicar los conocimientos a la práctica } \\
\text { Empatía } \\
\text { Expresar ideas y defender derechos sin agredir } \\
\text { Capacidad para hacerte entender }\end{array}$ \\
\hline & $\begin{array}{c}6 \\
\text { Motivación por } \\
\text { comunicación } \\
\text { eficiente }\end{array}$ & $\begin{array}{l}\text { Liderazgo } \\
\text { Motivación por la calidad } \\
\text { Comunicación oral y escrita en lengua extranjera } \\
\text { Utilizar herramientas informáticas }\end{array}$ \\
\hline & $\begin{array}{c}7 \\
\text { Habilidades de } \\
\text { adaptabilidad }\end{array}$ & $\begin{array}{l}\text { Pensamiento analítico y capacidad de síntesis } \\
\text { Rendir bajo presión } \\
\text { Comunicación oral y escrita en lengua materna }\end{array}$ \\
\hline \multirow{3}{*}{$\begin{array}{c}\text { Poco } \\
\text { sólido }\end{array}$} & 8 & $\begin{array}{l}\text { Sensibilidad temas sociales } \\
\text { Sensibilidad medioambiental }\end{array}$ \\
\hline & 9 & $\begin{array}{l}\text { Búsqueda de información en diversas fuentes } \\
\text { Sexo }\end{array}$ \\
\hline & 10 & $\begin{array}{l}\text { Experiencia laboral } \\
\text { Curso }\end{array}$ \\
\hline
\end{tabular}

Cuadro 2. Resumen de las variables que explican o se agrupan en los factores _IT

Cuando se repite el análisis excluyendo de la matriz de variables el sexo, la experiencia laboral y el curso, los resultados, en lo que se refiere a la varianza explicada y solidez de los factores extraídos, no difieren a lo expuesto previamente.

La tabla 7 muestra un extracto de la tabla 1.3 del anexo 1 que permite, para cada variable analizada, expresarla como combinación lineal de los distintos factores extraídos. Así, a modo de ejemplo, para las dos primeras variables, según la matriz de componentes rotados extraídos por el método Varimax con Kaixer, las variables tienden a saturar en algún factor con peso factorial elevado, y bajo en el resto:

\begin{tabular}{|c|c|c|c|c|c|c|c|c|c|}
\hline & \multicolumn{9}{|c|}{ Componente } \\
\hline & 1 & 2 & 3 & 4 & 5 & 6 & 7 & 8 & 9 \\
\hline Autoevaluación emocional & ,730 & ,366 & ,126 &, 135 &, 080 &, 127 & ,049 &, 078 &, 080 \\
\hline \multicolumn{10}{|c|}{$\begin{array}{l}\text { Autoevaluación emocional }=0,730 \text { F1+ ,366 F2 }+, 126 \text { F3+ ,135 F4+ ,080 F5+,127 F6+,049 } \\
\text { F7+, } 078 \text { F8+,080 F9 }\end{array}$} \\
\hline Orientación al logro & ,710 &, 108 &, 157 &, 148 &, 143 &, 226 &, 141 &,- 073 &,- 042 \\
\hline
\end{tabular}

Tabla 7: Extracto de la Tabla 1.3 del anexo 1: Matriz de componentes rotados (_PU)

Por último, la matriz de coeficientes, tablas 1.4 y 2.4 de los anexos 1 y 2 respectivamente, muestra las puntuaciones factoriales obtenidas por cada competencia, esto es, 
las ponderaciones que determinan cada componente extraído como una combinación lineal de las variables del estudio, y que permitiría, si ese fuese el objetivo del trabajo, definir unos indicadores sintéticos del grado de desarrollo competencial de un estudiante y su percepción de la relevancia en el entorno laboral.

De nuevo, a modo de ejemplo de interpretación de tales puntuaciones factoriales, de la tabla 8, obtenida de la tabla 1.4 del anexo 1, se extraen los pesos asociados al Factor 1 en el caso de la pregunta_PU. Se han señalado en negrita los menores y mayores pesos factoriales, y en el caso de éstos últimos resaltados con sombreado gris. En concreto, las variables "búsqueda de información en diversas fuentes, hacerte entender; relaciones personales, compromiso ético en el trabajo, sensibilidad medioambiental, aplicar los conocimientos a la práctica y negociar de forma eficaz, experiencia laboral y curso" no tienen apenas contribución en la configuración del factor 1 , con pesos en valor absoluto entre ,003 y, 019, mientras que "negociar de forma eficaz, autoconciencia emocional, autoevaluación emocional, confianza en uno mismo, empatía, orientación al logro, expresar ideas y defender derechos sin agredir" son las variables que más aportan en la formación de dicho factor, en todos los casos con pesos que oscilan en valor absoluto del 0,210 al 0,283.

\begin{tabular}{|l|r|l|r|}
\hline Pensamiento analítico y capacidad de síntesis &,- 104 & Liderazgo &, 076 \\
\hline Organización y planificación &, 029 & Iniciativa y espíritu emprendedor & -050 \\
\hline $\begin{array}{l}\text { Comunicación oral y escrita en lengua mater- } \\
\text { na }\end{array}$ &, 035 & Motivación por la calidad &, 060 \\
\hline $\begin{array}{l}\text { Comunicación oral y escrita en lengua extran- } \\
\text { jera }\end{array}$ &,- 085 & Sensibilidad medioambiental & - \\
\hline Utilizar herramientas informáticas &,- 029 & Sensibilidad temas sociales &, $\mathbf{0 1 1}$ \\
\hline $\begin{array}{l}\text { Búsqueda de información en diversas } \\
\text { fuentes }\end{array}$ & $\mathbf{0 1 3}$ & Aplicar los conocimientos a la práctica &, 035 \\
\hline Resolución de conflictos o problemas &, 027 & Búsqueda de información e investigación & - \\
\hline Toma de decisiones &,- 040 & Diseño y gestión de proyectos &, 054 \\
\hline Conocimientos de otras áreas o disciplinas &,- 062 & Divulgación de las cuestiones económicas & - \\
\hline Adquirir con rapidez nuevos conocimientos &, 043 & Presentar en público productos ideas o informes &,- 092 \\
\hline Hacerte entender & $\mathbf{, 0 1 4}$ & Negociar de forma eficaz &, 021 \\
\hline $\begin{array}{l}\text { Trabajar en equipo de carácter multidiscipli- } \\
\text { nar }\end{array}$ &,- 095 & Redactar informes o documentos & $\mathbf{, 0 0 3}$ \\
\hline Trabajo en un contexto internacional &,- 210 & Autoconciencia emocional &, 067 \\
\hline Relaciones personales & $\mathbf{- , 0 1 1}$ & Autoevaluación emocional \\
\hline $\begin{array}{l}\text { Trabajar en entornos diversos y multicultura- } \\
\text { les }\end{array}$ &,- 092 & Confianza en uno mismo &, $\mathbf{2 5 0}$ \\
\hline
\end{tabular}




\begin{tabular}{|l|r|l|r|}
\hline Capacidad crítica y autocrítica &,- 033 & Empatía & $\mathbf{, 2 4 9}$ \\
\hline Compromiso ético en el trabajo & $\mathbf{- , 0 0 3}$ & Orientación al logro & $\mathbf{, 2 8 3}$ \\
\hline Rendir bajo presión &,- 045 & $\begin{array}{l}\text { Expresar ideas y defender derechos sin agre- } \\
\text { dir }\end{array}$ & $\mathbf{, 2 3 5}$ \\
\hline Usar el tiempo de forma efectiva &, 097 & Experiencia laboral & $\mathbf{, 0 0 6}$ \\
\hline Aprendizaje autónomo &,- 079 & Curso & $\mathbf{, 0 0 8}$ \\
\hline Adaptación a nuevas situaciones &,- 040 & Sexo &, 041 \\
\hline Creatividad &,- 085 & & \\
\hline
\end{tabular}

Tabla 8. Puntuaciones factoriales, asociadas al Factor 1 en la pregunta_PU

\section{Discusión y conclusiones}

En este trabajo se aborda la exploración de las asimetrías entre el grado de desarrollo el "grado de desarrollo competencial en la formación Universitaria (_PU)" y la "importancia en el entorno laboral ( IT), desde la perspectiva del propio estudiante, junto con el análisis factorial de la matriz de variables, que permite extraer los factores sólidos y medio sólidos que validan el instrumento de evaluación.

Del análisis descriptivo de los datos se concluye que, en cuanto al grado de desarrollo o de formación en la Universidad, la opción más representativa es "regular", con porcentajes que oscilan entre el 27 y el 40\%, y se accede al escalón "mucho" respecto a la importancia que los estudiantes creen que tienen las distintas competencias en el entorno laboral, con porcentajes que van del $32 \%$ al $50 \%$, con excepciones en las que acumulan mayoritariamente a los estudiantes en la opción "bastante". Esta asimetría en la asignación de respuestas entre las opciones, se constata con los diferenciales de la valoración: Así, mientras que para la importancia en el trabajo en general la media obtenida es superior a 3,2, llegando a la cota superior de alrededor de 4,3, en cuanto al grado de preparación, las medias oscilan entre el 2,1 y el 3,4. Además, las distintas segmentaciones confirman la norma general ya señalada: así, a) por curso matriculado, en general la valoración media que los estudiantes hacen del grado de preparación en las diversas competencias es mayor entre los que cursan quinto que entre los de cuarto, si bien para la importancia en el trabajo es al contario; b) en general, y en ambas preguntas, la valoración media entre los estudiantes de ADE es ligeramente menor que entre los de ECO. Estos resultados, que ponen de manifiesto la divergencia entre las dos preguntas, grado de formación y de adaptabilidad al entorno laboral, son coherentes con los obtenidos en otros trabajos, como el de Palmer, Montaño y Palou (2009). Estos autores, con un cuestionario análogo y la misma escala de valoración de Likert, encuestan a académicos y empleadores y constatan claras asimetrías en la importancia de la formación en competencias y el grado de realización de las mismas.

En cuanto al análisis factorial de carácter exploratorio realizado, es pertinaz, según justifica tanto el valor del determinante de la matriz de correlaciones de las variables cercano a 0 , como los índices Kaiser-Meyer-Olkin $(>0,93)$ y los contrastes de esfericidad de Barlett. En la matriz _PU se identifican 9 factores o componentes con un valor propio inicial superior a 1 , que llegan a explicar conjuntamente el 59,6\% de la varianza, mientras que en la matriz _IT, se identifican 10 factores, que si bien conjuntamente 
llegan a explicar el 57,22\%, son algo más inestables. Así, cabe distinguir cuatro factores "sólidos", tanto en la matriz_PU, como en la matriz_IT, mientras que serían "medio sólidos", los factores 5 y 6 en la matriz _PU y los factores 5, 6 y 7 en la_IT, siendo el resto de factores obtenidos inestables en la estructura del constructo analizado. Esta estructura de factores latentes configura un indicador sintético para evaluar el grado de desarrollo de las competencias adquiridas y el grado potencial de inserción laboral de los estudiantes universitarios. Estos resultados confirman los obtenidos en otros trabajos, como el de Solanes, Núñez y Rodríguez (2008) a partir de un cuestionario análogo, en el que con 45 items o competencias determinan 6 factores y explican el 53,15\% de la varianza.

Cabe abordar este tipo de análisis como una medida más para conocer la eficiencia de la formación universitaria recibida, fuera del propio rendimiento académico de los estudiantes y el grado de aprendizaje de los conocimientos específicos de la titulación estudiada, desde el enfoque de la adecuación de los títulos a los perfiles y necesidades de grados de competencias profesionales en el entorno laboral de los egresados. El trabajo, que analiza las asimetrías detectadas entre la valoración personal y subjetiva de los propios estudiantes, trata de recoger algunas de las críticas habituales de los responsables de recursos humanos, cuando señalan la distancia real entre la formación académica de los regresados y su capacidad de desarrollo profesional, que exige en muchos casos un extenso y costoso período de entrenamiento para su adaptación. Disponer de esta información, no cabe duda, que es importante tanto para las distintas instituciones responsables, como para los cuadros docentes, que pueden diseñar actividades de aprendizaje de las materias buscando el efecto añadido de desarrollar ciertas competencias requeridas para una satisfactoria inserción laboral.

La extracción de los factores perfila una herramienta, o indicador, de evaluación del grado de desarrollo en la formación universitaria de las competencias genéricas o transversales, que se ajuste a las necesidades de los perfiles competenciales requeridas en el entorno laboral. Este tipo de indicador puede ser relevante para todos los agentes, tanto para el propio estudiante (conocer su grado de desarrollo, necesidades de formación para mejora de su empleabilidad, etc.), para las instituciones (identificación de las necesidades formativas en competencias, adecuación/intervención en contenidos curriculares, desarrollo del sistema feed-back, mejora de la calidad docente, etc.), como para las empresas u organismos contratantes (indicador del potencial competencial).

Para finalizar, señalar que disponer de este tipo de herramientas es un elemento adicional para conocer la calidad de la formación, que va más allá de los contenidos específicos de las titulaciones y que aborda una formación en competencias genéricas que han de formar parte de los perfiles de los egresados para aumentar su potencial empleabilidad, así como las actitudes y compromisos personales. No olvidemos la apuesta de la Universidad española por una docencia basada en el aprendizaje activo, potenciando el saber hacer, sin desdeñar el saber ser o estar. 


\section{Referencias bibliográficas}

BALBUENA, C., CASAS, J. R. (2003). Aplicación del análisis factorial a la valoración por parte de los estudiantes de las asignaturas de la ETSICCP de Barcelona en sus distintas titulaciones. Meeting on Civil Engineering Education. Ciudad Real. Recuperado (25, 06, 2010):http://wwwma3.upc.edu/users/balbuena/CiudadReal.pdf

CLIMENT, J. B. (2010). Reflexiones sobre la Educación Basada en Competencias. Revista Complutense de Educación. Vol. 21 Núm. 1, pps. 91-106

HENSON, R. K. Y ROBERTS, J. K. (2006). Use of Exploratory Factor Analysis in Published Research: Common Errors and Some Comment on Improved Practice. Educational and Psychological Measurement, 66, pps. 393-416.

HOLMES, L. (2000). Questioning the skills agenda, en S. Fallows y C. Steven (comps.) Integrating key skills in higher education, 201-214. Londres: Kogan Page

IGLESIA M.C. Y IONITA, C. (2010), Percepción de la necesidad de un desarrollo competencial en los estudios de economía y administración de empresas. Documento de trabajo $\mathrm{n}^{\circ}$, Enero 2010, Instituto de Análisis Industrial y Financiero. UCM.

IRIONDO I. (coord.), Gallego, E., Grandal, M.D., Gracia, E., Iglesia, M.C. (2009). Inserción Profesional de las principales licenciaturas de la UCM. Informe 2008. Ed. Ecobook

KLINE, P. (1994), An Easy Guide to Factor Analysis. Newbury Park: Sage.

MASSEILOT, H. (2000). Competencias laborales y procesos de certificación ocupacional. En: CINTERFOR-OIT. Competencias laborales en la formación profesional. Boletín Técnico Interamericano de Formación Profesional. $\mathrm{N}^{\mathrm{o}} 149$.

MORALES, P. (2010). El análisis factorial en la construcción e interpretación de tests, escalas y cuestionarios. Universidad Pontificia Comillas, Madrid. Recuperado (25, 06, 2010): www.upcomillas.es/personal/peter/investigacion/Analisis Factorial.pdf

NUNNALLY, J. C. (1978). Psychometric Theory. New York: McGraw-Hill.

PALMER, A., MONTAÑO, J. J., Y PALOU, M. (2009). Las competencias genéricas en la educación superior. Estudio comparativo entre la opinión de empleadores y académicos. Psicothema, Vol 21, nº 3, pp 433-438

SLADOGNA, M. G. (2000). Una mirada a la construcción de las competencias desde el sistema educativo. La experiencia Argentina, En: CINTERFOR-OIT. Competencias laborales en la formación profesional. Boletín Técnico Interamericano de Formación Profesional. N ${ }^{\circ} 149$

SOLANES, A., NÚÑEZ, R., Y RODRÍGUEZ, J. (2008). Elaboración de un cuestionario para la evaluación de competencias genéricas en estudiantes universitarios. Apuntes de Psicología, Vol. 26, nº 1, pp. 35-49.

VARGAS, F. (2000). De las virtudes laborales a las competencias claves: un nuevo concepto para antiguas demandas. En: CINTERFOR-OIT. Competencias laborales 
en la formación profesional. Boletín Técnico Interamericano de Formación Profesional. $\mathrm{N}^{\mathrm{o}} 149$

VINACUA, V. (1998). Análisis estadístico con SPSS para Windows, Vol. II. Estadistica Multivariante. Mc Graw Hill. Madrid

THORNDIKE, R. L. (1982). Applied Psychometrics, Boston: Houghton-Mifflin

\section{Otras consultas}

Instituto Nacional para el Empleo (1995) Metodología para la ordenación de la formación profesional ocupacional. Subdirección General de Gestión de Formación Ocupacional. Madrid.

\section{Correspondencia con la autora}

$\mathrm{M}^{\mathrm{a}}$ Covadonga de la Iglesia

Universidad Complutense de Madrid

Facultad de Ciencias Económicas y Empresariales

Campus de Somosaguas, Madrid 28223

Tlf.: (+34) 913943022

Fax: (+34) 913942561

E-mail: civ@ccee.ucm.es 


\section{Anexo 1. Análisis factorial (_PU)}

Tabla 1.1 Comunalidades. Análisis de Componentes principales (_PU)

\begin{tabular}{|c|c|c|}
\hline & Inicial & Extracción \\
\hline Pensamiento analítico y capacidad de síntesis & 1,000 & $\mathbf{7 0 7}$ \\
\hline Organización y planificación & 1,000 & ,636 \\
\hline Comunicación oral y escrita en lengua materna & 1,000 & ,446 \\
\hline Comunicación oral y escrita en lengua extranjera & 1,000 & ,646 \\
\hline Capacidad de utilizar herramientas informáticas & 1,000 & ,649 \\
\hline Habilidad para búsqueda de información en diversas fuentes & 1,000 & ,550 \\
\hline Resolución de conflictos o problemas & 1,000 & ,606 \\
\hline Toma de decisiones & 1,000 & ,546 \\
\hline Conocimientos de otras áreas o disciplinas & 1,000 & ,459 \\
\hline Adquirir con rapidez nuevos conocimientos & 1,000 & ,597 \\
\hline Capacidad para hacerte entender & 1,000 & 570 \\
\hline Trabajar en equipo de carácter multidisciplinar & 1,000 & ,431 \\
\hline Trabajo en un contexto internacional & 1,000 & ,679 \\
\hline Habilidad en relaciones personales & 1,000 & ,529 \\
\hline Trabajar en entornos diversos y multiculturales & 1,000 & ,586 \\
\hline Capacidad critica y autocrítica & 1,000 & ,518 \\
\hline Compromiso ético en el trabajo & 1,000 & ,482 \\
\hline Rendir bajo presión & 1,000 &, 574 \\
\hline Usar el tiempo de forma efectiva & 1,000 &, 511 \\
\hline Aprendizaje autónomo & 1,000 & 5,569 \\
\hline Adaptación a nuevas situaciones & 1,000 & ,599 \\
\hline Creatividad & 1,000 & ,550 \\
\hline Liderazgo & 1,000 & ,606 \\
\hline Iniciativa y espíritu emprendedor & 1,000 & ,569 \\
\hline Motivación por la calidad & 1,000 & ,499 \\
\hline Sensibilidad medioambiental & 1,000 & ,703 \\
\hline Sensibilidad temas sociales & 1,000 & ,711 \\
\hline Aplicar los conocimientos a la práctica & 1,000 & ,620 \\
\hline Habilidad de búsqueda de información e investigación & 1,000 & ,628 \\
\hline Diseño y gestión de proyectos & 1,000 & ,662 \\
\hline Capacidad para la divulgación de las cuestiones económicas & 1,000 & ,574 \\
\hline Presentar en público productos ideas o informes & 1,000 & ,670 \\
\hline Negociar de forma eficaz & 1,000 & ,622 \\
\hline Redactar informes o documentos & $\mathbf{1 , 0 0 0}$ & ,481 \\
\hline Autoconciencia emocional & 1,000 & ,695 \\
\hline Autoevaluación emocional & 1,000 & ,738 \\
\hline Confianza en uno mismo & 1,000 & ,694 \\
\hline Empatía & 1,000 & ,657 \\
\hline Orientación al logro & 1,000 & ,661 \\
\hline Expresar ideas y defender derechos sin agredir & 1,000 & 5,548 \\
\hline Experiencia laboral & 1,000 & ,552 \\
\hline Curso & 1,000 & 561 \\
\hline Sexo & $\mathbf{1 , 0 0 0}$ & ,740 \\
\hline
\end{tabular}


Tabla 1.2 Varianza total explicada. Método de extracción: Componentes principales (_PU) (primeros 15 componentes)

\begin{tabular}{|c|c|c|c|c|c|c|c|c|c|}
\hline \multirow[b]{2}{*}{ Componente } & \multicolumn{3}{|c|}{ Autovalores iniciales } & \multicolumn{3}{|c|}{$\begin{array}{l}\text { Sumas de las saturaciones al } \\
\text { cuadrado de la extracción }\end{array}$} & \multicolumn{3}{|c|}{$\begin{array}{c}\text { Suma de las saturaciones al } \\
\text { cuadrado de la rotación }\end{array}$} \\
\hline & Total & $\begin{array}{c}\% \text { de la } \\
\text { varianza }\end{array}$ & \begin{tabular}{|c|}
$\%$ \\
acumu- \\
lado
\end{tabular} & Total & $\begin{array}{c}\% \text { de la } \\
\text { varianza }\end{array}$ & \begin{tabular}{|c|}
$\%$ acumu- \\
lado
\end{tabular} & Total & $\begin{array}{c}\% \text { de la } \\
\text { varianza }\end{array}$ & $\begin{array}{l}\text { \% acu- } \\
\text { mulado }\end{array}$ \\
\hline 1 & 15,113 & 35,146 & 35,146 & 15,113 & 35,146 & 35,146 & 5,074 & 11,800 & 11,800 \\
\hline 2 & 1,717 & 3,992 & 39,138 & 1,717 & 3,992 & 39,138 & 5,050 & 11,744 & 23,543 \\
\hline 3 & 1,581 & 3,676 & 42,814 & 1,581 & 3,676 & 42,814 & \begin{tabular}{|l|}
3,472 \\
\end{tabular} & 8,073 & 31,617 \\
\hline 4 & 1,418 & 3,298 & 46,112 & 1,418 & 3,298 & 46,112 & 2,941 & 6,840 & 38,457 \\
\hline 5 & 1,364 & 3,172 & 49,284 & 1,364 & 3,172 & 49,284 & \begin{tabular}{|l|}
2,482 \\
\end{tabular} & 5,772 & 44,229 \\
\hline 6 & 1,224 & 2,847 & 52,131 & 1,224 & 2,847 & 52,131 & 2,426 & 5,642 & 49,871 \\
\hline 7 & 1,111 & 2,585 & 54,716 & 1,111 & 2,585 & 54,716 & \begin{tabular}{|l|}
1,571 \\
\end{tabular} & 3,653 & 53,524 \\
\hline 8 & 1,084 & 2,521 & 57,237 & 1,084 & 2,521 & 57,237 & \begin{tabular}{|l|}
1,319 \\
\end{tabular} & 3,067 & 56,590 \\
\hline 9 & 1,017 & 2,365 & 59,602 & 1,017 & 2,365 & 59,602 & 1,295 & 3,011 & 59,602 \\
\hline 10 & ,970 & 2,255 & 61,857 & & & & & & \\
\hline 11 & ,893 & 2,076 & 63,933 & & & & & & \\
\hline 12 & 865 & 2,011 & 65,944 & & & & & & \\
\hline 13 & 821 & 1,908 & 67,852 & & & & & & \\
\hline 14 & ,795 & 1,848 & 69,701 & & & & & & \\
\hline 15 & ,743 & 1,727 & 71,428 & & & & & & \\
\hline
\end{tabular}

Tabla 1.3 Matriz de componentes $\operatorname{rotados}^{\mathrm{a}}$ (_PU)

\begin{tabular}{|l|c|c|c|c|c|r|r|r|c|}
\hline & \multicolumn{9}{|c|}{ Componente } \\
\cline { 2 - 9 } & $\mathbf{1}$ & $\mathbf{2}$ & $\mathbf{3}$ & $\mathbf{4}$ & $\mathbf{5}$ & $\mathbf{6}$ & \multicolumn{1}{c|}{$\mathbf{7}$} & $\mathbf{8}$ & $\mathbf{9}$ \\
\hline Autoevaluación emocional & $\mathbf{, 7 3 0}$ &, 366 &, 126 &, 135 &, 080 &, 127 &, 049 &, 078 &, 080 \\
\hline Orientación al logro & $\mathbf{, 7 1 0}$ &, 108 &, 157 &, 148 &, 143 &, 226 &, 141 &,- 073 &,- 042 \\
\hline Autoconciencia emocional & $\mathbf{, 6 9 7}$ &, 346 &, 187 &, 130 &, 089 &, 153 &,- 030 &, 066 &, 024 \\
\hline Confianza en uno mismo & $\mathbf{, 6 9 5}$ &, 258 &, 185 &, 129 &, 060 &, 245 &, 164 &, 036 &, 047 \\
\hline Empatía & $\mathbf{, 6 7 5}$ &, 352 &, 152 &, 087 &, 192 &, 091 &,- 019 &, 033 &, 007 \\
\hline $\begin{array}{l}\text { Expresar ideas y defender derechos sin } \\
\text { agredir }\end{array}$ & $\mathbf{, 6 2 4}$ &, 182 &, 166 &, 267 &, 058 &, 090 &, 043 &,- 067 &, 094 \\
\hline Usar el tiempo de forma efectiva & $\mathbf{, 4 0 6}$ &, 109 &, 296 &, 242 &, 271 &, 135 &, 223 &, 216 &, 025 \\
\hline Sensibilidad medioambiental &, 296 & $\mathbf{, 7 6 4}$ &, 075 &, 010 &, 128 &, 015 &, 051 &, 048 &,- 058 \\
\hline Sensibilidad temas sociales &, 371 & $\mathbf{, 7 2 0}$ &, 080 &, 065 &, 127 &,- 046 &, 149 &, 047 &,- 035 \\
\hline Trabajo en un contexto internacional &, 030 & $\mathbf{, 6 0 3}$ &, 448 &, 270 &, 062 &, 178 &, 058 &,- 018 &, 035 \\
\hline Creatividad &, 223 & $\mathbf{, 5 3 8}$ &, 151 &, 238 &, 143 &, 312 &, 075 &, 090 &,- 007 \\
\hline $\begin{array}{l}\text { Trabajar en entornos diversos y multi- } \\
\text { culturales }\end{array}$ &, 192 & $\mathbf{, 5 0 3}$ &, 277 &, 400 &, 109 &, 113 &,- 035 &,- 037 &, 180 \\
\hline Iniciativa y espíritu emprendedor &, 275 & $\mathbf{, 4 9 6}$ &, 258 &, 117 &, 107 &, 392 &,- 038 &, 008 &, 019 \\
\hline Liderazgo &, 246 & $\mathbf{, 4 8 0}$ &, 084 &, 332 &,- 040 &, 419 &, 106 &, 024 &, 094 \\
\hline
\end{tabular}




\begin{tabular}{|c|c|c|c|c|c|c|c|c|c|}
\hline Compromiso ético en el trabajo & ,274 & ,470 & ,306 & , 197 &,- 006 &,- 013 &, 186 &, 136 &, 024 \\
\hline $\begin{array}{l}\text { Capacidad para la divulgación de las } \\
\text { cuestiones económicas }\end{array}$ & ,283 & ,464 &, 110 &, 046 & ,437 & ,209 & ,097 &,- 118 & ,073 \\
\hline $\begin{array}{l}\text { Conocimientos de otras áreas o disci- } \\
\text { plinas }\end{array}$ & , 161 & ,436 & ,341 &, 121 & , 188 & ,021 & , 141 & 210 &,- 112 \\
\hline Motivación por la calidad & ,406 & ,429 & ,194 &, 105 & ,248 & ,196 & ,010 &,- 039 & ,005 \\
\hline $\begin{array}{l}\text { Capacidad de utilizar herramientas } \\
\text { informáticas }\end{array}$ & , 178 & , 146 & ,697 &,- 104 & 236 & , 156 & ,064 &,- 079 & ,095 \\
\hline $\begin{array}{l}\text { Comunicación oral y escrita en lengua } \\
\text { extranjera }\end{array}$ & , 148 & ,345 & ,676 & ,018 & ,032 & , 127 & , 157 &,- 037 & ,066 \\
\hline Resolución de conflictos o problemas & ,293 & , 177 & ,504 & ,417 & , 142 &,- 009 &,- 136 &,- 032 & , 143 \\
\hline $\begin{array}{l}\text { Comunicación oral y escrita en lengua } \\
\text { materna }\end{array}$ & ,254 & 087 & ,486 & 230 & ,020 & ,031 & ,212 & , 178 &,- 082 \\
\hline $\begin{array}{l}\text { Habilidad para búsqueda de informa- } \\
\text { ción en diversas fuentes }\end{array}$ & 265 & , 188 & ,455 & ,083 & ,397 & ,036 & ,225 &,- 134 & ,057 \\
\hline Toma de decisiones & ,221 &, 106 & ,423 & ,391 & ,208 & ,306 &,- 079 &,- 020 &, 103 \\
\hline $\begin{array}{l}\text { Trabajar en equipo de carácter multi- } \\
\text { disciplinar }\end{array}$ &, 100 & ,240 & ,356 & ,261 &,- 017 & ,281 & ,057 & 270 &,- 118 \\
\hline Rendir bajo presión & ,116 & ,018 &,- 095 & ,652 & , 108 & , 186 & ,225 & ,099 &,- 136 \\
\hline Adaptación a nuevas situaciones & ,248 & ,363 & ,092 & ,517 & ,334 & ,096 & ,018 & ,031 & ,091 \\
\hline Habilidad en relaciones personales_ & ,295 & ,280 & ,215 & ,503 &, 146 &, 184 & ,035 &, 020 &, 092 \\
\hline Capacidad critica y autocrítica & 264 & ,352 & ,212 & ,482 & ,090 & , 128 & , 137 &,- 024 & ,051 \\
\hline Capacidad para hacerte entender & ,261 & , 160 & ,400 & ,419 & ,252 &,- 007 & ,071 & 245 &,- 108 \\
\hline Aprendizaje autónomo & ,015 & ,027 & 056 & ,304 & ,678 & ,023 & ,090 &,- 010 &,- 061 \\
\hline $\begin{array}{l}\text { Habilidad de búsqueda de información } \\
\text { e investigación }\end{array}$ & ,227 & ,360 & , 195 &, 105 & ,549 & ,238 &, 188 &,- 061 &,- 010 \\
\hline Aplicar los conocimientos a la práctica & , 193 & , 175 & ,273 &,- 090 & ,526 & ,325 &,- 059 & ,285 &, 044 \\
\hline $\begin{array}{l}\text { Adquirir con rapidez nuevos conoci- } \\
\text { mientos }\end{array}$ & 277 & , 199 &, 154 & ,343 & ,435 &,- 124 & ,273 & ,216 &,- 116 \\
\hline $\begin{array}{l}\text { Presentar en público productos ideas o } \\
\text { informes }\end{array}$ &, 247 &, 056 &, 087 & ,132 & , 109 & ,732 &, 136 &, 087 &,- 083 \\
\hline Diseño y gestión de proyectos &, 211 & ,448 &, 116 & ,096 & ,399 & ,471 & 011 &,- 064 & 088 \\
\hline Negociar de forma eficaz & ,351 & ,400 & ,266 & , 147 & 084 & ,441 &,- 062 & ,203 &,- 001 \\
\hline Redactar informes o documentos & 371 &, 095 &, 105 & ,258 & , 146 & ,425 &, 164 &,- 028 &,- 164 \\
\hline $\begin{array}{l}\text { Pensamiento analítico y capacidad de } \\
\text { síntesis }\end{array}$ & ,027 &, 150 &, 100 & , 121 &, 185 & ,069 & ,777 &,- 115 &, 061 \\
\hline Organización y planificación & ,299 &, 104 & 327 & , 144 & ,043 & ,206 & ,558 & , 197 &, 113 \\
\hline Sexo & ,041 &,- 039 & 030 &,- 058 & ,002 &,- 067 & ,031 &,- 842 &,- 138 \\
\hline Experiencia laboral &,- 064 &,- 031 &,- 017 &,- 140 & ,037 &,- 029 & ,076 &,- 065 &,- 717 \\
\hline Curso & ,015 &,- 022 & ,071 &,- 157 & ,020 &,- 104 & , 192 & ,048 & ,693 \\
\hline \multicolumn{10}{|c|}{ Extracción: Análisis de componentes principales. Rotación: Normalización Varimax con Kaiser. } \\
\hline & & & & & & & & & \\
\hline
\end{tabular}


Tabla 1.4 Matriz de coeficientes para el cálculo de las puntuaciones en los componentes

\begin{tabular}{|c|c|c|c|c|c|c|c|c|c|}
\hline & \multicolumn{9}{|c|}{ Componente } \\
\hline & 1 & 2 & 3 & 4 & 5 & 6 & 7 & 8 & 9 \\
\hline $\begin{array}{l}\text { Pensamiento analítico y capacidad de } \\
\text { síntesis }\end{array}$ &,- 104 &, 037 &,- 075 &,- 014 &,- 009 &, 023 & ,605 &,- 121 &, 057 \\
\hline Organización y planificación & ,029 &,- 083 & ,062 &,- 055 &,- 123 & 072 & ,399 & ,115 &, 065 \\
\hline $\begin{array}{l}\text { Comunicación oral y escrita en lengua } \\
\text { materna }\end{array}$ & ,035 &,- 094 & ,231 & ,036 &,- 114 &,- 080 & ,090 & ,097 &,- 113 \\
\hline $\begin{array}{l}\text { Comunicación oral y escrita en lengua } \\
\text { extranjera }\end{array}$ &,- 085 & ,039 & ,338 &,- 106 &,- 127 & ,006 & ,056 &,- 074 &,- 014 \\
\hline Utilizar herramientas informáticas &,- 029 &,- 093 & ,372 &,- 188 & ,060 & ,038 &,- 044 &,- 089 & 017 \\
\hline $\begin{array}{l}\text { Búsqueda de información en diversas } \\
\text { fuentes }\end{array}$ & ,013 &,- 065 & ,164 &,- 071 &, 165 &,- 084 & ,074 &,- 131 & ,016 \\
\hline Resolución de conflictos o problemas &, 027 &,- 088 & 223 &, 195 &,- 005 &,- 137 &,- 228 &,- 088 &, 073 \\
\hline Toma de decisiones &,- 040 &,- 134 & 163 &, 158 & ,030 &, 120 &,- 171 &,- 085 & ,069 \\
\hline Conocimientos de otras áreas o disciplinas &,- 062 & ,127 & ,092 &,- 055 & ,020 &,- 110 & ,043 &, 150 &,- 127 \\
\hline Adquirir con rapidez nuevos conocimientos & ,043 &,- 019 &,- 056 & ,088 & 213 &,- 242 & ,110 &, 157 &,- 098 \\
\hline Hacerte entender &, 014 &,- 077 & 137 &, 145 &, 064 &,- 156 &,- 064 & ,151 &,- 115 \\
\hline \begin{tabular}{|l|}
$\begin{array}{l}\text { Trabajar en equipo de carácter multidis- } \\
\text { ciplinar }\end{array}$ \\
\end{tabular} &,- 095 & ,013 &, 142 & ,056 &,- 135 & ,117 &,- 009 &, 164 &,- 120 \\
\hline Trabajo en un contexto internacional &,- 210 & ,208 & ,149 & ,071 &,- 114 & 022 &,- 016 &,- 074 &,- 010 \\
\hline Relaciones personales &,- 011 &,- 013 & \begin{tabular}{|l|}
,- 012 \\
\end{tabular} & 231 &,- 026 &, 005 &,- 061 &,- 052 &, 069 \\
\hline $\begin{array}{l}\text { Trabajar en entornos diversos y multi- } \\
\text { culturales }\end{array}$ &,- 092 & ,134 & ,022 &, 176 &,- 049 &,- 042 &,- 103 &,- 090 & ,124 \\
\hline Capacidad critica y autocrítica &,- 033 & 048 &,- 015 & ,221 &,- 081 &,- 031 & ,036 &,- 086 & 031 \\
\hline ico en el trabajo &,- 003 & ,141 & ,059 & ,013 &,- 135 &,- 134 & ,098 & ,075 &,- 024 \\
\hline Rendir bajo presión &,- 045 &,- 071 &,- 166 & ,368 &,- 030 & ,056 & , 126 & ,012 &,- 070 \\
\hline Usar el tiempo de forma efectiva &, 097 &,- 122 & ,042 & ,006 &, 078 &,- 035 &, 080 &, 140 &, 002 \\
\hline Aprendizaje autónomo &,- 079 &,- 084 &,- 078 &, 116 & ,443 &,- 075 &,- 042 &,- 019 &,- 015 \\
\hline Adaptación a nuevas situaciones &,- 040 & 050 &,- 116 & ,238 & ,130 &,- 075 &,- 084 &,- 026 & 083 \\
\hline Creatividad &,- 085 &, 161 &,- 068 &, 024 &,- 032 &, 106 & ,009 &, 030 &,- 012 \\
\hline Lide &,- 076 &, 133 &,- 107 & ,111 &,- 176 & ,209 & 059 &,- 044 &, 077 \\
\hline Iniciativa y espíritu emprendedor &,- 050 &, 114 &, 025 &,- 052 &,- 053 & ,174 &,- 083 &,- 034 &,- 003 \\
\hline Motivación por la calidad & ,060 & 070 &,- 025 &,- 061 & ,068 & 007 &,- 064 &,- 052 &,- 013 \\
\hline Sensibilidad medioambiental &,- 011 & ,329 &,- 112 &,- 115 &,- 012 &,- 130 &, 012 & ,039 &,- 075 \\
\hline Sensibilidad temas sociales &, 035 & ,293 &,- 123 &,- 085 &,- 025 &,- 185 & 083 &, 034 &,- 058 \\
\hline Aplicar los conocimientos a &,- 019 &,- 063 & ,049 &,- 221 & ,330 & 134 &,- 143 & 235 & ,030 \\
\hline Búsqueda de información e investigación &,- 054 &, 039 &,- 050 &,- 082 & ,278 & ,049 &, 055 &,- 064 &,- 001 \\
\hline Diseño y gestión de proyectos &,- 092 & ,088 &,- 097 &,- 074 & ,176 & ,240 &,- 057 &,- 079 &, 085 \\
\hline Divulgación de las cuestiones económicas &,- 018 &, 111 &,- 102 &,- 099 &, 214 &, 033 &, 007 &,- 104 &, 061 \\
\hline $\begin{array}{l}\text { Presentar en público productos ideas o } \\
\text { informes }\end{array}$ &,- 021 &,- 122 &,- 048 &,- 046 &,- 042 & ,482 & ,077 & ,021 &,- 041 \\
\hline Negociar de forma eficaz &, 00 &, 041 &, 030 & 055 & 063 &, 196 & 110 & 122 &,- 021 \\
\hline
\end{tabular}




\begin{tabular}{|l|r|r|r|r|r|r|r|r|r|}
\hline Redactar informes o documentos &, 067 &,- 108 &,- 042 &, 050 &,- 025 &, 214 &, 073 &,- 069 &,- 119 \\
\hline Autoconciencia emocional &, 250 &,- 015 &,- 028 &,- 057 &,- 045 &,- 055 &,- 097 &, 031 &,- 013 \\
\hline Autoevaluación emocional &, 268 &, 000 &,- 085 &,- 057 &,- 054 &,- 074 &,- 027 &, 042 &, 035 \\
\hline Confianza en uno mismo &, 243 &,- 067 &,- 038 &,- 067 &,- 090 &, 033 &, 068 &,- 002 &, 013 \\
\hline Empatía &, 249 &,- 003 &,- 052 &,- 084 &, 041 &,- 101 &,- 094 &, 017 &,- 022 \\
\hline Orientación al logro &, 283 &,- 151 &,- 029 &,- 039 &,- 018 &, 025 &, 037 &,- 087 &,- 047 \\
\hline $\begin{array}{l}\text { Expresar ideas y defender derechos sin } \\
\text { agredir }\end{array}$ &, 235 &,- 088 &,- 022 &, 074 &,- 066 &,- 072 &,- 039 &,- 092 &, 054 \\
\hline Experiencia laboral &, 006 &, 028 &, 071 &,- 105 &, 009 &,- 028 &, 070 &,- 026 &,- 574 \\
\hline Curso &, 008 &,- 020 &,- 024 &,- 102 &, 040 &,- 039 &, 163 &, 046 &, 542 \\
\hline Sexo &, 041 &,- 017 &, 080 &, 045 &,- 030 &,- 012 &, 033 &,- 684 &,- 105 \\
\hline
\end{tabular}

Extracción: Análisis de componentes principales. Rotación: Normalización Varimax con Kaiser. Puntuaciones de componentes.

Anexo 2. Análisis factorial ( IT)

Tabla 2.1 Comunalidades. Análisis de Componentes principales (_IT)

\begin{tabular}{|l|r|r|}
\hline & Inicial & Extracción \\
\hline Pensamiento analítico y capacidad de síntesis & 1,000 &, 513 \\
\hline Organización y planificación & 1,000 &, 663 \\
\hline Comunicación oral y escrita en lengua materna & 1,000 &, 564 \\
\hline Comunicación oral y escrita en lengua extranjera & 1,000 &, 569 \\
\hline Capacidad de utilizar herramientas informáticas & 1,000 &, 598 \\
\hline Habilidad para búsqueda de información en diversas fuentes & 1,000 &, 615 \\
\hline Resolución de conflictos o problemas & 1,000 &, 517 \\
\hline Toma de decisiones & 1,000 &, 554 \\
\hline Conocimientos de otras áreas o disciplinas & 1,000 &, 524 \\
\hline Adquirir con rapidez nuevos conocimientos & $\mathbf{1 , 0 0 0}$ & $\mathbf{, 4 7 7}$ \\
\hline Capacidad para hacerte entender & 1,000 &, 549 \\
\hline Trabajar en equipo de carácter multidisciplinar & $\mathbf{1 , 0 0 0}$ & $\mathbf{, 4 7 3}$ \\
\hline Trabajo en un contexto internacional & 1,000 &, 623 \\
\hline Habilidad en relaciones personales & 1,000 &, 564 \\
\hline Trabajar en entornos diversos y multiculturales & 1,000 &, 647 \\
\hline Capacidad critica y autocrítica & $\mathbf{1 , 0 0 0}$ & $\mathbf{4 6 6}$ \\
\hline Compromiso ético en el trabajo & $\mathbf{1 , 0 0 0}$ & $\mathbf{, 4 9 6}$ \\
\hline Usar el tiempo de forma efectiva & 1,000 &, 546 \\
\hline Aprendizaje autónomo & $\mathbf{1 , 0 0 0}$ & $\mathbf{, 4 1 9}$ \\
\hline Adaptación a nuevas situaciones & 1,000 &, 527 \\
\hline Creatividad & 1,000 &, 527 \\
\hline Liderazgo & 1,000 &, 636 \\
\hline Iniciativa y espíritu emprendedor & 1,000 &, 547 \\
\hline Motivación por la calidad & 1,000 &, 601 \\
\hline Sensibilidad medioambiental & $\mathbf{1 , 0 0 0}$ & $\mathbf{, 7 2 9}$ \\
\hline
\end{tabular}




\begin{tabular}{|l|r|r|}
\hline Sensibilidad temas sociales & $\mathbf{1 , 0 0 0}$ & $\mathbf{, 7 4 6}$ \\
\hline Aplicar los conocimientos a la práctica & 1,000 &, 590 \\
\hline Habilidad de búsqueda de información e investigación & 1,000 &, 645 \\
\hline Diseño y gestión de proyectos & 1,000 &, 551 \\
\hline Capacidad para la divulgación de las cuestiones económicas & 1,000 &, 538 \\
\hline Presentar en público productos ideas o informes & 1,000 &, 659 \\
\hline Negociar de forma eficaz & 1,000 &, 533 \\
\hline Redactar informes o documentos & 1,000 &, 508 \\
\hline Autoconciencia emocional & $\mathbf{1 , 0 0 0}$ &, $\mathbf{7 7 0}$ \\
\hline Autoevaluación emocional & $\mathbf{1 , 0 0 0}$ &, $\mathbf{7 7 5}$ \\
\hline Confianza en uno mismo & 1,000 &, 575 \\
\hline Empatía & 1,000 &, 614 \\
\hline Orientación al logro & 1,000 &, 549 \\
\hline Expresar ideas y defender derechos sin agredir & 1,000 &, 531 \\
\hline Sexo & 1,000 &, 597 \\
\hline Experiencia laboral & 1,000 &, 606 \\
\hline Curso & 1,000 &, 539 \\
\hline
\end{tabular}

Tabla 2.2 Varianza total explicada. Método de extracción: Componentes principales ( IT) (15 primeros)

\begin{tabular}{|c|c|c|c|c|c|c|c|c|c|}
\hline \multirow[b]{2}{*}{ Componente } & \multicolumn{3}{|c|}{ Autovalores iniciales } & \multicolumn{3}{|c|}{$\begin{array}{l}\text { Sumas de las saturaciones al } \\
\text { cuadrado de la extracción }\end{array}$} & \multicolumn{3}{|c|}{$\begin{array}{l}\text { Suma de las saturaciones al } \\
\text { cuadrado de la rotación }\end{array}$} \\
\hline & Total & $\begin{array}{c}\text { \% de la } \\
\text { varianza }\end{array}$ & $\begin{array}{l}\text { \% acu- } \\
\text { mulado }\end{array}$ & Total & $\begin{array}{c}\text { \% de la } \\
\text { varianza }\end{array}$ & $\begin{array}{l}\text { \% acumu- } \\
\text { lado }\end{array}$ & Total & $\begin{array}{c}\text { \% de la } \\
\text { varianza }\end{array}$ & $\begin{array}{l}\text { \% acu- } \\
\text { mulado }\end{array}$ \\
\hline 1 & 12,236 & 28,455 & 28,455 & 12,236 & 28,455 & 28,455 & 3,485 & 8,105 & 8,105 \\
\hline 2 & 2,136 & 4,966 & 33,421 & 2,136 & 4,966 & 33,421 & 3,226 & 7,503 & 15,608 \\
\hline$\overline{3}$ & 1,647 & 3,830 & 37,251 & 1,647 & 3,830 & 37,251 & 3,174 & 7,382 & 22,990 \\
\hline 4 & 1,490 & 3,464 & 40,715 & 1,490 & 3,464 & 40,715 & 3,170 & 7,371 & 30,362 \\
\hline 5 & 1,393 & 3,240 & 43,955 & 1,393 & 3,240 & 43,955 & 2,354 & 5,475 & 35,836 \\
\hline 6 & 1,265 & 2,941 & 46,897 & 1,265 & 2,941 & 46,897 & 2,211 & 5,142 & 40,979 \\
\hline 7 & 1,189 & 2,765 & 49,662 & 1,189 & 2,765 & 49,662 & 1,989 & 4,626 & 45,604 \\
\hline 8 & 1,158 & 2,693 & 52,354 & 1,158 & 2,693 & 52,354 & 1,964 & 4,568 & 50,172 \\
\hline 9 & 1,064 & 2,474 & 54,828 & 1,064 & 2,474 & 54,828 & 1,702 & 3,957 & 54,129 \\
\hline 10 & 1,031 & 2,397 & 57,226 & 1,031 & 2,397 & 57,226 & 1,332 & 3,097 & 57,226 \\
\hline 11 & ,968 & 2,251 & 59,477 & & & & & & \\
\hline 12 & ,878 & 2,042 & 61,519 & & & & & & \\
\hline 13 & ,874 & 2,033 & 63,552 & & & & & & \\
\hline 14 & ,827 & 1,922 & 65,474 & & & & & & \\
\hline 15 & ,814 & 1,894 & 67,368 & & & & & & \\
\hline
\end{tabular}


Tabla 2.3 Matriz de componentes $\operatorname{rotados}^{\mathrm{a}}($ IT)

\begin{tabular}{|c|c|c|c|c|c|c|c|c|c|c|}
\hline & \multicolumn{10}{|c|}{ Componente } \\
\hline & 1 & 2 & 3 & 4 & 5 & 6 & 7 & 8 & 9 & 10 \\
\hline Compromiso ético en el trabajo & ,661 & ,099 &, 117 &, 101 & ,013 & , 165 & ,102 & ,110 & ,133 &,- 059 \\
\hline $\begin{array}{l}\text { Presentar en público productos } \\
\text { ideas o informes }\end{array}$ & ,653 & ,005 & 126 & ,057 & , 108 &,- 025 & ,081 & , 157 &,- 115 & ,121 \\
\hline Iniciativa y espíritu emprendedor &, $\mathbf{5 3 1}$ & ,127 &, 131 & ,210 & ,072 & , 183 & ,266 & 214 &,- 021 &, 024 \\
\hline Toma de decisiones & ,483 &, 107 & ,202 & ,225 &, 123 & ,262 &,- 050 & 056 &, 287 &,- 011 \\
\hline Creatividad & ,419 & ,194 & ,104 & ,342 &,- 054 & 239 & ,193 & 320 &,- 055 &,- 023 \\
\hline $\begin{array}{l}\text { Resolución de conflictos o proble- } \\
\text { mas }\end{array}$ & ,363 & ,167 &, 174 & ,109 & ,096 & ,214 & ,056 & ,131 & ,360 &, 083 \\
\hline $\begin{array}{l}\text { Trabajar en entornos diversos y } \\
\text { multiculturales }\end{array}$ &,- 061 & ,757 & ,078 & ,167 & ,193 & ,253 &,- 002 & , 182 & , 148 &, 051 \\
\hline Diseño y gestión de proyectos &,- 024 & ,753 & ,076 & ,172 & , 175 & ,238 & ,029 & ,192 & ,167 & ,003 \\
\hline Adaptación a nuevas situaciones & ,329 & ,583 & ,133 & ,112 & ,330 &,- 170 & ,026 & ,035 & ,049 &, 039 \\
\hline Autoconciencia emocional & 232 &, 542 & 257 &, 040 & ,152 & , 126 & ,223 &,- 106 &,- 044 &,- 116 \\
\hline Negociar de forma eficaz & 419 &, 533 &, 174 &, 123 &,- 046 & 088 & ,199 &,- 063 &, 114 &,- 020 \\
\hline Relaciones personales & 459 & ,482 & ,227 &, 049 &, 015 & 068 & ,154 & 050 & ,028 & ,092 \\
\hline Orientación al logro & 192 & ,043 &, 632 &, 048 & 247 & 081 & ,135 & 024 & ,343 &, 030 \\
\hline $\begin{array}{l}\text { Trabajar en equipo d } \\
\text { multidisciplinar }\end{array}$ & ,210 & ,206 & ,614 & ,217 & ,015 & ,129 & , 101 & ,006 & ,078 &, 050 \\
\hline Redactar informes o documentos & ,144 & 241 & ,591 & ,348 &,- 037 &,- 003 & ,149 & 281 &,- 074 &,- 050 \\
\hline Confianza en uno mismo &,- 038 & ,140 &, 564 & ,221 & 259 & , 165 & ,142 & , 162 &, 060 & ,020 \\
\hline Capacidad crítica y autocrítica & ,283 &,- 037 &, 518 &,- 017 & ,071 & ,152 & ,077 & 289 & ,342 &,- 063 \\
\hline $\begin{array}{l}\text { Búsqueda de información e investi- } \\
\text { gación }\end{array}$ & ,336 &, 227 &, 433 & ,286 &,- 042 &, 034 &, 003 & ,287 &,- 053 &,- 022 \\
\hline Autoevaluación emocional & ,273 & 291 & ,389 &, 119 & ,072 &,- 031 &, 070 & ,384 &, 060 & ,036 \\
\hline $\begin{array}{l}\text { Divulgación de las cuestiones eco- } \\
\text { nómicas }\end{array}$ & ,081 &, 005 &, 158 &, 698 & ,186 & ,244 & ,107 & ,059 &, 008 &,- 007 \\
\hline $\begin{array}{l}\text { Trabajo en un contexto internacio- } \\
\text { nal }\end{array}$ &, 105 & ,209 & ,208 &, 696 & ,220 &, 042 &, 046 &,- 014 &, 122 &,- 006 \\
\hline $\begin{array}{l}\text { Conocimientos de otras áreas o } \\
\text { disciplinas }\end{array}$ & ,446 & ,118 & ,067 & ,523 &, 125 &, 050 & ,021 & ,035 & 220 & ,051 \\
\hline $\begin{array}{l}\text { Adquirir con rapidez nuevos cono- } \\
\text { cimientos }\end{array}$ & , 182 & ,036 & ,169 &, 463 &,- 079 &,- 059 & ,449 & ,239 &,- 087 &,- 107 \\
\hline Aprendizaje autónomo &, 060 & ,269 &, 167 & ,449 & ,105 & 252 & ,013 & 221 & , 135 &,- 015 \\
\hline Usar el tiempo de forma efectiva & ,178 &, 186 & ,335 &, 422 & 161 & ,358 &,- 013 & ,008 &, 046 &,- 089 \\
\hline Organización y planificación & ,294 & ,021 & 079 & ,415 & 117 & , 183 & ,247 & 203 &, 186 & ,149 \\
\hline $\begin{array}{l}\text { Aplicar los conocimientos a la } \\
\text { práctica }\end{array}$ &, 075 &, 153 &, 063 &, 189 & ,798 & ,077 &, 056 &, 118 & ,072 &,- 018 \\
\hline Empatía & ,044 & 224 &, 133 & ,183 & ,764 & 059 &, 039 & ,076 &, 184 &,- 117 \\
\hline $\begin{array}{l}\text { Expresar ideas y defender derechos } \\
\text { sin agredir }\end{array}$ & ,206 &, 158 & ,265 &, 071 & ,443 & ,353 & ,096 &, 005 &,- 262 &, 128 \\
\hline Capacidad para hacerte entender & ,276 & ,238 &, 112 & ,325 & ,328 & ,086 & ,117 & ,164 & 296 & 0 \\
\hline
\end{tabular}




\begin{tabular}{|c|c|c|c|c|c|c|c|c|c|c|}
\hline Liderazgo &, 152 & ,066 & ,337 &, 180 & ,022 & ,647 &,- 017 & ,096 &,- 130 &,- 092 \\
\hline Motivación por la calidad & ,280 & 233 &,- 104 & ,134 & 013 &, 527 & 218 &, 170 & , 185 & 025 \\
\hline $\begin{array}{l}\text { Comunicación oral y escrita en } \\
\text { lengua extranjera }\end{array}$ & ,080 & ,200 & ,050 & , 192 & ,303 &, 503 &, 191 & ,122 &, 145 &, 130 \\
\hline Utilizar herramientas informáticas & , 157 & ,211 & ,388 & ,345 &, 045 &, 419 & , 102 & ,070 &,- 044 &,- 134 \\
\hline $\begin{array}{l}\text { Pensamiento analítico y capacidad } \\
\text { de síntesis }\end{array}$ & , 170 & , 108 & ,115 & ,203 &,- 130 &, 018 & ,649 &, 105 & , 175 & ,121 \\
\hline Rendir bajo presión & , 148 & , 195 & ,034 &,- 054 & ,183 &, 162 & ,641 & ,086 &,- 018 &,- 128 \\
\hline $\begin{array}{l}\text { Comunicación oral y escrita en } \\
\text { lengua materna }\end{array}$ & ,033 &,- 044 & ,307 & ,095 & 260 &, 092 & ,577 & 070 & 197, & 196 \\
\hline Sensibilidad temas sociales & ,209 & ,093 & ,091 & ,131 & 044 & ,197 & 162 & ,705 & ,148 &,- 035 \\
\hline Sensibilidad medioambiental & 137 &, 035 &, 169 &, 056 &, 158 &, 053 &, 079 &, 653 &, 027 &, 028 \\
\hline $\begin{array}{l}\text { Búsqueda de información en diver- } \\
\text { sas fuentes_ }\end{array}$ &, 010 &,- 178 &,- 119 &,- 121 &,- 105 &, 088 &,- 125 &,- 068 &,- 705 & ,141 \\
\hline Sexo & ,343 & , 126 & ,145 & , 138 &, 112 & ,283 & , 161 & 035 & ,375 & ,224 \\
\hline Experiencia laboral &,- 018 &, 003 &, 058 &,- 125 &,- 136 &, 020 &,- 081 & ,143 & ,001 & ,738 \\
\hline Curso &,- 117 &,- 009 & 070 &,- 085 &,- 065 &, 036 &,- 128 & ,148 & ,082 &,- 677 \\
\hline
\end{tabular}

Tabla 2.4 Matriz de coeficientes para el cálculo de las puntuaciones en los componentes ( IT)

\begin{tabular}{|l|c|c|c|c|c|c|c|c|c|c|}
\hline & \multicolumn{9}{|c|}{ Componente } \\
\cline { 2 - 11 } & $\mathbf{1}$ & $\mathbf{2}$ & $\mathbf{3}$ & $\mathbf{4}$ & $\mathbf{5}$ & $\mathbf{6}$ & $\mathbf{7}$ & $\mathbf{8}$ & $\mathbf{9}$ & $\mathbf{1 0}$ \\
\hline Compromiso ético en el trabajo &,- 032 &,- 050 &,- 022 &,- 075 &, 089 &,- 061 &,- 043 &, 474 &,- 062 &, 024 \\
\hline $\begin{array}{l}\text { Presentar en público productos } \\
\text { ideas o informes }\end{array}$ &,- 032 &,- 033 &,- 113 &,- 053 &,- 018 &, 039 &,- 003 &, 482 &, 033 &,- 033 \\
\hline Iniciativa y espíritu emprendedor &,- 015 &, 034 &,- 074 &,- 170 &, 079 &, 062 &, 454 &,- 024 &,- 101 &,- 153 \\
\hline Toma de decisiones &,- 036 &,- 033 &,- 028 &, 227 &,- 090 &,- 174 &, 264 &, 083 &,- 137 &,- 091 \\
\hline Creatividad &,- 072 &, 015 &,- 030 &, 052 &,- 149 &,- 066 &, 416 &,- 039 &, 077 &, 058 \\
\hline $\begin{array}{l}\text { Resolución de conflictos o proble- } \\
\text { mas }\end{array}$ &,- 128 &,- 118 &, 115 &,- 062 &, 102 &,- 007 &, 368 &,- 059 &, 066 &, 126 \\
\hline $\begin{array}{l}\text { Trabajar en entornos diversos y } \\
\text { multiculturales }\end{array}$ &, 194 &,- 043 &,- 074 &,- 011 &, 014 &, 012 &, 079 &, 042 &,- 102 &,- 027 \\
\hline Diseño y gestión de proyectos &, 100 &, 014 &,- 107 &, 089 &,- 089 &, 044 &, 025 &, 135 &,- 114 &,- 039 \\
\hline Adaptación a nuevas situaciones &,- 086 &,- 010 &,- 096 &,- 028 &, 084 &, 291 &, 062 &, 007 &, 041 &, 093 \\
\hline Autoconciencia emocional &, 074 &,- 045 &,- 022 &,- 042 &,- 024 &, 135 &, 002 &,- 096 &, 233 &, 147 \\
\hline Negociar de forma eficaz &, 036 &, 031 &,- 208 &,- 056 &,- 084 &, 331 &, 072 &, 032 &, 097 &,- 014 \\
\hline Relaciones personales &, 029 &,- 097 &,- 104 &, 162 &, 000 &, 013 &, 065 &, 048 &, 070 &, 102 \\
\hline Orientación al logro &,- 078 &,- 108 &,- 046 &, 362 &, 019 &, 038 &,- 006 &,- 055 &,- 056 &, 022 \\
\hline $\begin{array}{l}\text { Trabajar en equipo de carácter } \\
\text { multidisciplinar }\end{array}$ &, 166 &,- 051 &,- 112 &, 253 &,- 002 &,- 106 &,- 111 &,- 084 &, 100 &, 034 \\
\hline Redactar informes o documentos &,- 064 &, 008 &,- 012 &, 374 &, 014 &,- 134 &,- 057 &,- 111 &, 018 &, 034 \\
\hline Confianza en uno mismo &,- 111 &, 056 &,- 039 &, 182 &,- 057 &, 061 &,- 085 &, 087 &, 043 &, 020 \\
\hline Capacidad critica y autocrítica &, 056 &,- 001 &,- 087 &, 077 &, 106 &,- 073 &,- 022 &, 029 &, 126 &,- 055 \\
\hline
\end{tabular}




\begin{tabular}{|c|c|c|c|c|c|c|c|c|c|c|}
\hline $\begin{array}{l}\text { Búsqueda de información e investi- } \\
\text { gación }\end{array}$ & ,344 &,- 088 &,- 027 &,- 065 & , 108 &,- 119 &,- 052 & ,037 &,- 163 & 039 \\
\hline Autoevaluación emocional & 318 &,- 060 &,- 062 &,- 077 &,- 017 & ,031 &,- 045 &,- 043 & ,038 &,- 1 \\
\hline $\begin{array}{l}\text { Divulgación de las cuestiones eco- } \\
\text { nómicas }\end{array}$ &, 103 &,- 019 &,- 009 &,- 064 &,- 025 & ,078 &,- 076 &,- 010 & 218 & ,045 \\
\hline $\begin{array}{l}\text { Trabajo en un contexto internacio- } \\
\text { nal }\end{array}$ & ,198 &,- 076 &,- 006 &, 000 &,- 001 & ,097 &,- 164 &,- 085 &, 161 &,- 029 \\
\hline $\begin{array}{l}\text { Conocimientos de otras áreas o } \\
\text { disciplinas }\end{array}$ & 014 &,- 022 &, 083 & 125 & 011 & , 146 & ,099 &,- 117 &,- 024 &,- 051 \\
\hline $\begin{array}{l}\text { Adquirir con rapidez nuevos cono- } \\
\text { cimientos }\end{array}$ &,- 021 &,- 071 & , 112 &,- 057 &,- 059 & ,422 &,- 081 &,- 040 &,- 126 &,- 072 \\
\hline Aprendizaje autónomo &,- 051 &, 005 & ,117 & ,058 &,- 079 & ,201 &,- 004 &,- 080 &,- 089 &,- 095 \\
\hline Usar el tiempo de forma efectiva &, 053 &,- 035 & ,080 &,- 113 & ,249 & , 166 & ,011 &,- 072 &,- 289 & 082 \\
\hline y planificación & ,014 &,- 064 &,- 078 &,- 008 & ,450 &,- 069 &,- 020 & 061 &,- 076 &,- 008 \\
\hline $\begin{array}{l}\text { Aplicar los c } \\
\text { práctica }\end{array}$ &,- 011 &,- 027 &,- 032 &,- 021 & ,401 &,- 080 &,- 030 &, 014 & ,013 &,- 077 \\
\hline Empatía &, 048 &,- 136 & ,228 &,- 181 &,- 015 & 043 &,- 058 &, 095 & ,201 &,- 062 \\
\hline $\begin{array}{l}\text { Expresar ideas y d } \\
\text { sin agredir }\end{array}$ &,- 005 &,- 106 & ,324 &,- 136 & ,067 &,- 027 & ,003 &,- 124 &, 186 &, 020 \\
\hline Capacidad para ha &,- 025 &, 017 & ,301 &,- 004 &,- 087 &,- 015 &,- 019 &,- 139 & ,001 & ,047 \\
\hline Liderazgo &,- 170 &,- 029 & 263 &,- 008 & 067 & ,008 & ,031 &, 020 &,- 035 &, 043 \\
\hline Motivación $\mathrm{p}$ &,- 092 & 057 & 250 & ,095 &,- 107 &,- 154 & ,012 & ,096 &,- 134 &,- 013 \\
\hline $\begin{array}{l}\text { Comunicación oral y escrita en } \\
\text { lengua extranjera }\end{array}$ &, 061 &, 043 &, 143 & ,061 &,- 085 &,- 116 &,- 114 &, 114 &,- 110 &,- 009 \\
\hline Utilizar herramientas informáticas & ,020 & ,079 & , 120 &,- 054 &,- 014 &,- 155 &,- 063 & 210 &,- 041 &, 032 \\
\hline $\begin{array}{l}\text { Pensamiento analítico y capacidad } \\
\text { de síntesis }\end{array}$ &,- 170 & ,343 &,- 083 &,- 011 &,- 054 & ,059 &,- 048 & ,095 & ,050 & ,034 \\
\hline Rendir baj &,- 191 & ,349 &,- 074 &,- 008 &,- 043 & ,073 &,- 069 & ,096 & ,038 &, 076 \\
\hline $\begin{array}{l}\text { Comunicación oral y escrita en } \\
\text { lengua materna }\end{array}$ & , 126 & 217 &,- 004 &,- 043 &,- 129 &,- 040 & ,063 &,- 173 & ,022 &,- 042 \\
\hline Sensibilidad temas sociales & ,124 & ,236 &,- 025 &,- 024 &, 135 &,- 268 &,- 062 &,- 029 &,- 070 & ,027 \\
\hline Sensibilidad medioambiental &, 150 &, 185 & ,031 &,- 098 &,- 061 &,- 063 &, 014 &,- 072 &,- 055 &, 042 \\
\hline $\begin{array}{l}\text { Búsqueda de información en diver- } \\
\text { sas fuentes }\end{array}$ &, 040 & ,217 &, 074 &,- 114 & ,004 &,- 004 & ,122 &,- 185 &,- 113 &,- 107 \\
\hline Sexo & ,093 &,- 032 &,- 002 &,- 015 & ,061 & ,111 &,- 033 & ,020 &,- 498 & ,094 \\
\hline Experiencia laboral &,- 085 & 042 &, 069 &,- 039 &,- 077 & 023 &,- 113 &, 135 &, 023 & ,577 \\
\hline Curso &,- 019 &,- 008 & ,037 &,- 094 & -,049 & ,057 &,- 055 &, 120 & ,074 &,- 507 \\
\hline
\end{tabular}

